\title{
Warm Spiral Streamers over Gulf Stream Warm-Core Rings
}

\author{
WeIFENG (GORdON) ZHANG AND DENNIS J. MCGILLICUdDy JR. \\ Applied Ocean Physics and Engineering Department, Woods Hole Oceanographic Institution, Woods Hole, Massachusetts
}

(Manuscript received 5 February 2020, in final form 31 August 2020)

\begin{abstract}
This study examines the generation of warm spiral structures (referred to as spiral streamers here) over Gulf Stream warm-core rings. Satellite sea surface temperature imagery shows spiral streamers forming after warmer water from the Gulf Stream or newly formed warm-core rings impinges onto old warm-core rings and then intrudes into the old rings. Field measurements in April 2018 capture the vertical structure of a warm spiral streamer as a shallow lens of low-density water winding over an old ring. Observations also show subduction on both sides of the spiral streamer, which carries surface waters downward. Idealized numerical model simulations initialized with observed water-mass densities reproduce spiral streamers over warm-core rings and reveal that their formation is a nonlinear submesoscale process forced by mesoscale dynamics. The negative density anomaly of the intruding water causes a density front at the interface between the intruding water and surface ring water, which, through thermal wind balance, drives a local anticyclonic flow. The pressure gradient and momentum advection of the local interfacial flow push the intruding water toward the ring center. The large-scale anticyclonic flow of the ring and the radial motion of the intruding water together form the spiral streamer. The observed subduction on both sides of the spiral streamer is part of the secondary cross-streamer circulation resulting from frontogenesis on the stretching streamer edges. The surface divergence of the secondary circulation pushes the side edges of the streamer away from each other, widens the warm spiral on the surface, and thus enhances its surface signal.
\end{abstract}

KEYWORDS: Buoyancy; Eddies; Frontogenesis/frontolysis; Mesoscale processes; Transport; Vertical motion

\section{Introduction}

The Gulf Stream in the northwestern Atlantic Ocean often develops large-amplitude meanders (e.g., Andres 2016; Fuglister 1963) that sometimes pinch off from the main stream forming mesoscale anticyclonic eddies, so-called warm-core rings (WCRs), to the north of the Gulf Stream (e.g., Chaudhuri et al. 2009b; Joyce 1984). WCRs migrate within the Slope Sea-the deep ocean between the continental slope off the northeast coast of North America and the Gulf Stream. While migrating, WCRs interact with other features in the region: the continental shelf and shelf break front to the northwest (e.g., Chaudhuri et al. 2009a; Cherian and Brink 2018; Zhang and Gawarkiewicz 2015), the Gulf Stream to the south (Evans et al. 1985; Nof 1986), and other WCRs in the Slope Sea. Here we investigate the formation of warm spiral filaments over old WCRs. We refer to them as warm spiral streamers, as they have similar dimensions as the shelf-water streamers around WCRs (e.g., Cenedese et al. 2013). The spiral streamers form in the Slope Sea after the old WCRs come into contract with the Gulf Stream or newly formed rings with warmer surface waters (e.g., Smith and Baker 1985). Figure 1 shows some representative warm spiral streamers over WCRs in the Slope Sea. The development of a warm spiral streamer in June 2012 (Fig. 2) shows that as the warm streamer winds around the ring, its nose moves in the radial direction toward the ring center creating an inward radial offset between the nose and tail and forming a spiral pattern. Spiral streamers cause intrusion of water into WCRs and are a part of the exchange processes between WCRs and the surrounding waters that are important for

\footnotetext{
Corresponding author: Weifeng (Gordon) Zhang, wzhang@ whoi.edu
}

marine biogeochemistry and biology (Boyd et al. 1986; Fox and Kester 1986; Olson and Backus 1985).

Spiral filaments are ubiquitous in the ocean (e.g., Hua et al. 2013; Munk et al. 2000; Song et al. 2011). Some spiral filaments form around mesoscale eddies, and they can be generated by lateral straining of the tracer field (e.g., Gilbert 1988; Meunier et al. 2019; Smith and Ferrari 2009), instability-induced entrainment processes (e.g., de Marez et al. 2020; Stern 1987), or process of eddy merging (von Hardenberg et al. 2000). For instance, Stern (1987) argued that spiral filaments on the periphery of a cyclonic mesoscale eddy could be generated by shear instability of the azimuthal flow deforming the potential vorticity isopleth and entraining the surrounding waters. Submesoscale spiral features on the ocean surface with a horizontal length scale of $O(1-10 \mathrm{~km})$ are generated by mixed layer baroclinic instability, shear instability, or inertial instability (Buckingham et al. 2017; Eldevik and Dysthe 2002; Munk et al. 2000; Shen and Evans 2002). The warm spiral streamers over anticyclonic WCRs that this study focuses on have a horizontal length scale of $O(100 \mathrm{~km})$. As will be demonstrated here, they are formed by a different mechanism, where both mesoscale processes of the rings and frontal submesoscale processes are important.

Dynamics of the warm spiral streamers over WCRs as depicted by the satellite images in Figs. 1 and 2 are largely unexplored, and few studies have focused on their formation mechanism. Nof (1986) investigated the process of a WCR colliding with the Gulf Stream and depicted the pattern of a thin surface filament of Gulf Stream water moving around the ring and merging back into Gulf Stream on the other side of the ring. A thin filament forms a surface loop around the WCR, which differs from the warm spiral streamer of the interest of this study. Chapman and Nof (1988) presented a theory for 

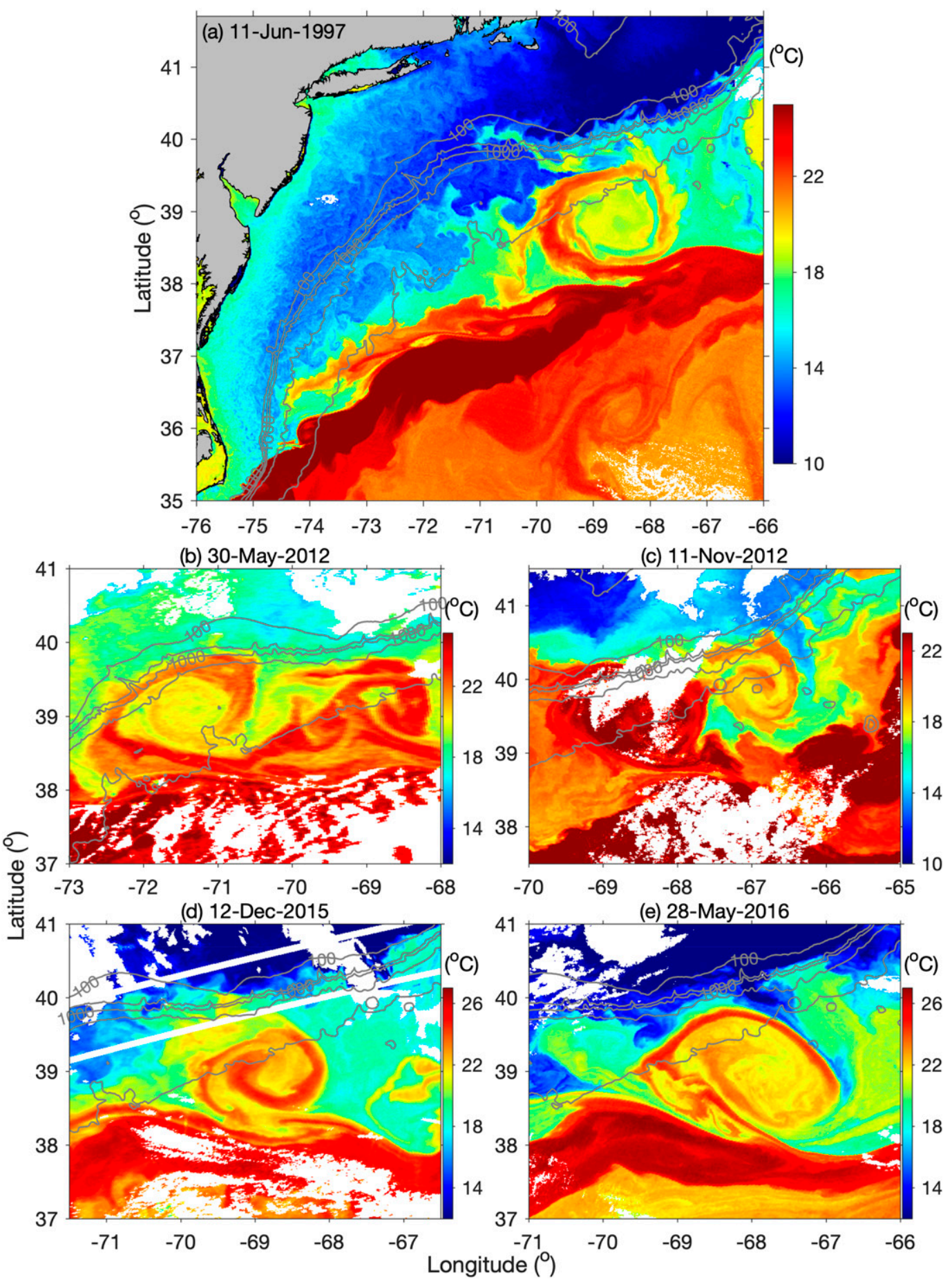

FIG. 1. Representative images of satellite-measured sea surface temperature showing warm spiral streamers over Gulf Stream warm-core rings at selected times. The gray lines are isobath contours. The white areas are cloud cover.

overwash of a WCR by the surrounding slope water, as the ring sinks into the ambient slope water due to cooling of the ring. They acknowledged that slope-water overwash of the ring would be uniform in the azimuthal direction and their theory does not explain the observed warm spiral streamers.
Chapman and Nof (1988) argued that spiral streamers could result from three different mechanisms: (i) temperature gradients in the overwashing surface water, (ii) fronts in the underlying ring water interacting with rotary motion of the overwashing water, and (iii) instability in the buoyant surface 


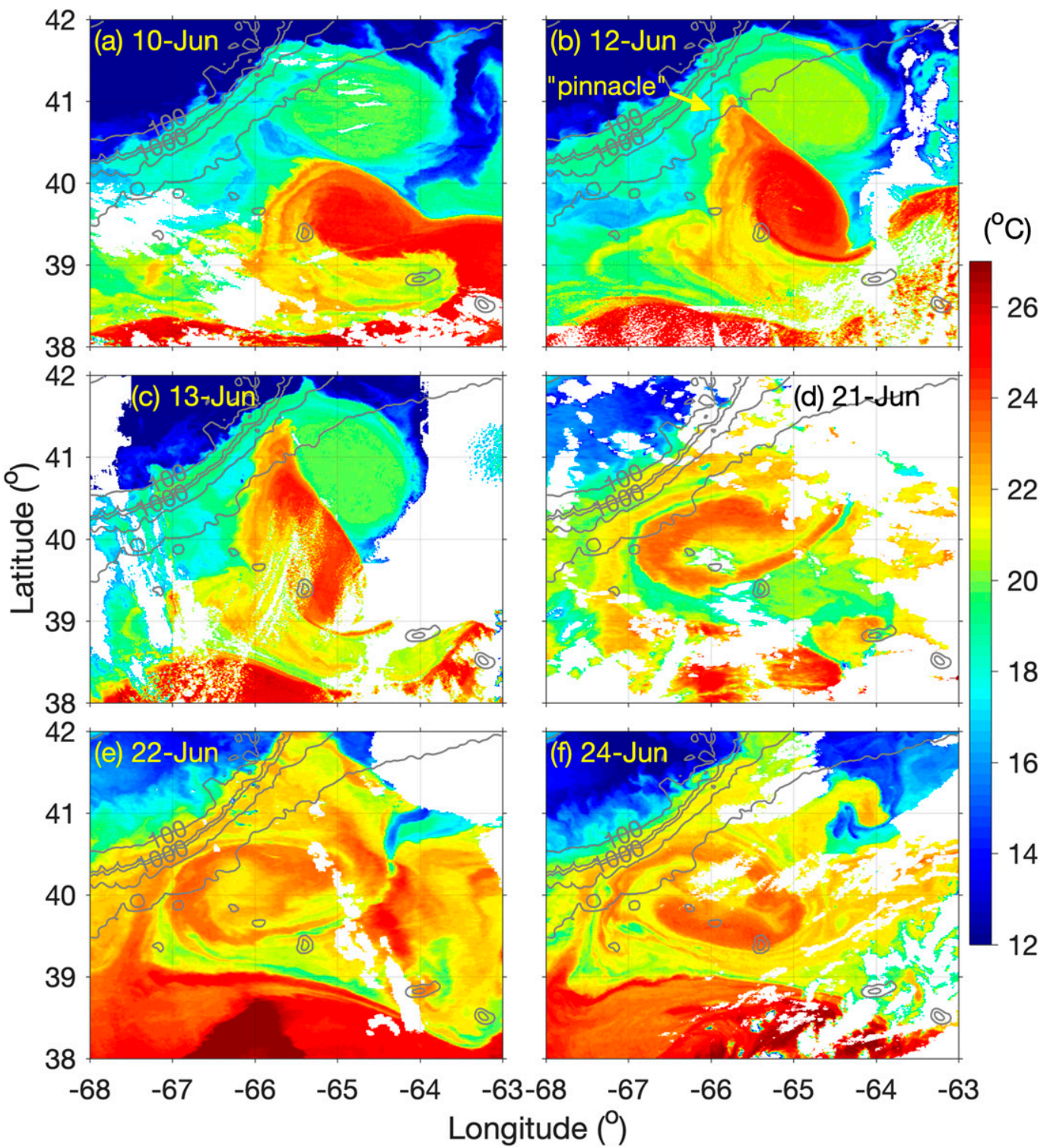

FIG. 2. Images of satellite-measured sea surface temperature showing the development and evolution of a warm spiral streamer in June 2012. The white areas are cloud cover.

water concentrates the overwash event into a single spiral band. However, the dynamics of the last two mechanisms are unspecified, and it is unclear whether the proposed mechanisms are responsible for the observed warm spirals. Moreover, as the cross-stream length scale of observed spiral streamers is much smaller than the radius of a mesoscale WCR, formation of the spiral streamers likely involves submesoscale dynamics (McWilliams 2016). How submesoscale processes affect the spiral streamers is unclear. For example, frontal subduction, which is a secondary submesoscale flow that tends to relax an intensifying front (e.g., Gula et al. 2014; Mahadevan and Tandon 2006; Spall 1995), may play a role in the development of warm spiral streamers. Motivated by these unknowns, this study examines the process of warm spiral streamers forming over WCRs in the Slope Sea and investigates the underlying dynamics.

\section{Methods}

This study utilizes both observations and models. Observations depict patterns of the warm spirals, and idealized models initialized with observed water mass characteristics are analyzed to reveal mechanism of spiral formation.

\section{a. Observations}

Remote sensing data from satellites at selected times in 1997-2018 and in situ measurements from research expedition AR29 of R/V Neil Armstrong at the Mid-Atlantic Bight 
(MAB) shelf break on 16-30 April 2018 are examined here. Snapshots of satellite-measured sea surface temperature (SST) with a horizontal resolution of $\sim 1 \mathrm{~km}$ give a surface view of the warm spiral streamers and their development (Figs. 1-3). AR29 was part of the Shelfbreak Productivity Interdisciplinary Research Operation at the Pioneer Array (SPIROPA) project to study biological productivity at the MAB shelf break front. Several of the AR29 cross-shelf transects with a towed Video Plankton Recorder (VPR; Davis et al. 2005) and lowered conductivity-temperature-depth (CTD) serendipitously went across a warm spiral streamer. Vertical profiles of temperature, salinity, fluorescence, and dissolved oxygen from a VPR transect and a CTD transect reveal the subsurface structure of a warm spiral streamer (Fig. 4). The VPR undulated within the depth range of 5-100 $\mathrm{m}$ on 26 April with the ship underway at $10 \mathrm{kt}\left(1 \mathrm{kt} \approx 0.51 \mathrm{~m} \mathrm{~s}^{-1}\right)$. The mean horizontal distance between neighboring up- and downcasts was about $450 \mathrm{~m}$, and the profiles were interpolated onto a vertical grid of $0.5 \mathrm{~m}$ for visualization. The CTD profiles were taken at cross-shelforiented stations that were $\sim 7.7 \mathrm{~km}$ apart on 27 April. The profile data were averaged onto a vertical grid of $1 \mathrm{~m}$. Note that the large horizontal spacing between neighboring CTD stations causes the thin subsurface high chlorophyll layer to appear disconnected (see section 3a). However, the connection is clear in the higher-resolution VPR data. For the temperaturesalinity plot, CTD profile data were averaged onto vertical bins of $2 \mathrm{~m}$ (Fig. 5).

\section{b. Modeling}

The Regional Ocean Modeling System (Shchepetkin and McWilliams 2008), a primitive equation, free-surface, hydrostatic model widely used for regional ocean simulations, is used here to solve the nonlinear hydrostatic momentum equations and a density equation (no separate temperature or salinity equations). ROMS uses structured rectangular grid with highorder numerical schemes. The model has a rectangular domain of $2010.5 \mathrm{~km}$ in $x$ and $479 \mathrm{~km}$ in $y$ directions and a 1005 -m-deep flat bottom. It simulates the deep sea and neglects the continental shelf or slope. Even though the in situ measurements were taken near the MAB shelf edge, the spiral formation does not require the sloping topography and often occurs in deep regions far away from the continental slope (see below). Model horizontal resolution is $500 \mathrm{~m}$ in both $x$ and $y$ directions in the central study region of $500 \mathrm{~km} \times 350 \mathrm{~km}$ and decreases to $2 \mathrm{~km}$ on the boundaries. The 500-m horizontal resolution has been proven to be high enough to resolve submesoscale frontal processes at the edge of a WCR (Zhang and Partida 2018). There are 60 vertical levels. Periodic boundary conditions are applied in the $x$ direction. Wall conditions are applied on the northern boundary to mimic the steep continental slope to the northwest of the MAB Slope Sea, and wave radiation conditions are applied on the southern boundary. Explicit horizontal viscosity and diffusivity are 0 in the central study region and increase outward reaching $100 \mathrm{~m}^{2} \mathrm{~s}^{-1}$ on the open boundaries. Note that implicit numerical viscosity and diffusivity from the horizontal advection schemes (third-order upstream for momentum and MPDATA for density) exist everywhere in the domain. A general length scale vertical turbulence closure $k-k l$ scheme (Warner et al. 2005) and quadratic bottom drag with coefficient of 0.003 are used. There is no surface forcing.

The initial density field consists of three water masses: background slope water, a circular old WCR, and a shallow eddy with water more buoyant than the old WCR (hereafter referred to as buoyant eddy) (Fig. 6). Density of the slope water is horizontally uniform and varies vertically following an observed profile in the MAB Slope Sea with a surface value of $\rho_{s}=1026.7 \mathrm{~kg} \mathrm{~m}^{-3}$. The buoyant eddy is to represent the edge of a newly formed WCR or the northern flank of the meandering Gulf Stream where the warm water layer is relative shallow (e.g., Halkin and Rossby 1985; Meinen and Luther 2016). It is this shallow layer of warm water that interacts with the old WCR and forms the warm spiral streamer (see below). Using the buoyant eddy in the model also avoids having the Gulf Stream going through the open boundaries. Both the WCR and the buoyant eddy have density anomaly relative to the slope water (Fig. 2a) specified by

$$
\Delta \rho(x, y, z)=\frac{1}{2}\left[1-\tanh \left(\frac{d-d_{c}}{d_{b}}\right)\right] e^{-z^{2} / H^{2}} \Delta \rho_{0} .
$$

Here, $\Delta \rho_{0}$ is the surface density anomaly at the ring/eddy center $\left(x_{0}, y_{0}\right), d=\left[\left(x-x_{0}\right)^{2}+\left(y-y_{0}\right)^{2}\right]^{1 / 2}, d_{c}$ is the ring/eddy radius to the maximum velocity, $d_{b}$ is the horizontal length scale of the ring/eddy-edge transition region, and $H$ is the ring/eddy vertical scale. Hereinafter, subscripts $r$ and $e$ are added to these variables to differentiate the ring and the buoyant eddy.

For the WCR, its center is located at the origin of the Cartesian coordinate system, that is, $x_{0, r}=0$ and $y_{0, r}=0$. Its physical characteristics are $d_{c, r}=60 \mathrm{~km}, d_{b, r}=30 \mathrm{~km}, H_{r}=$ $500 \mathrm{~m}$, and $\Delta \rho_{0, r}=-0.5 \mathrm{~kg} \mathrm{~m}^{-3}$, representative of WCRs in the Slope Sea with a typical density difference between the ring and slope waters (e.g., Joyce and McDougall 1992). Density of the surface ring water is thus $\rho_{r}=\rho_{s}+\Delta \rho_{0, r}=1026.2 \mathrm{~kg} \mathrm{~m}^{-3}$. Initial conditions of the WCR are the same in all simulations.

The shallow buoyant eddy is located to the southwest of the ring with an eddy-ring distance that allows them to interact with each other. In the control case, $x_{0, e}=-90 \mathrm{~km}$, $y_{0, e}=-170 \mathrm{~km}, d_{c, e}=60 \mathrm{~km}, d_{b, e}=5 \mathrm{~km}, H_{e}=150 \mathrm{~m}$, and $\Delta \rho_{0, e}=-1 \mathrm{~kg} \mathrm{~m}^{-3}$. The surface density of the eddy water is thus $\rho_{e}=\rho_{s}+\Delta \rho_{0, e}=1025.7 \mathrm{~kg} \mathrm{~m}^{-3}$ with $\rho_{e}<\rho_{r}<\rho_{s}$, consistent with the observations (see below). The mean buoyancy frequencies in the ring and eddy are $N_{r} \approx 0.006 \mathrm{~s}^{-1}$ and $N_{e} \approx$ $0.001 \mathrm{~s}^{-1}$, respectively. Most of the simulations presented in this study, including the Control Run, use uniform Coriolis parameter, $f=f_{0}=9.37 \times 10^{-5} \mathrm{~s}^{-1}\left(40^{\circ} \mathrm{N}\right)$, and the ring and the buoyant eddy do not propagate laterally. To examine the sensitivity of the solution to the model parameters, simulations with different $\Delta \rho_{0, e}$, different $\left(x_{0, e}, y_{0, e}\right)$, and spatially varying $f\left(f=f_{0}+\beta y\right)$ are conducted (Table 1$)$. Most of the sensitivity simulations deviate from Control Run by only one parameter, except Beta Run, which branches off the Low Density Anomaly (LDA) Run 2 to show whether ring propagation can induce spiral formation (see below).

Thermal-wind-balanced horizontal velocity (assuming zero bottom velocity) and geostrophically balanced sea level tilt are included in the initial conditions of all simulations. 


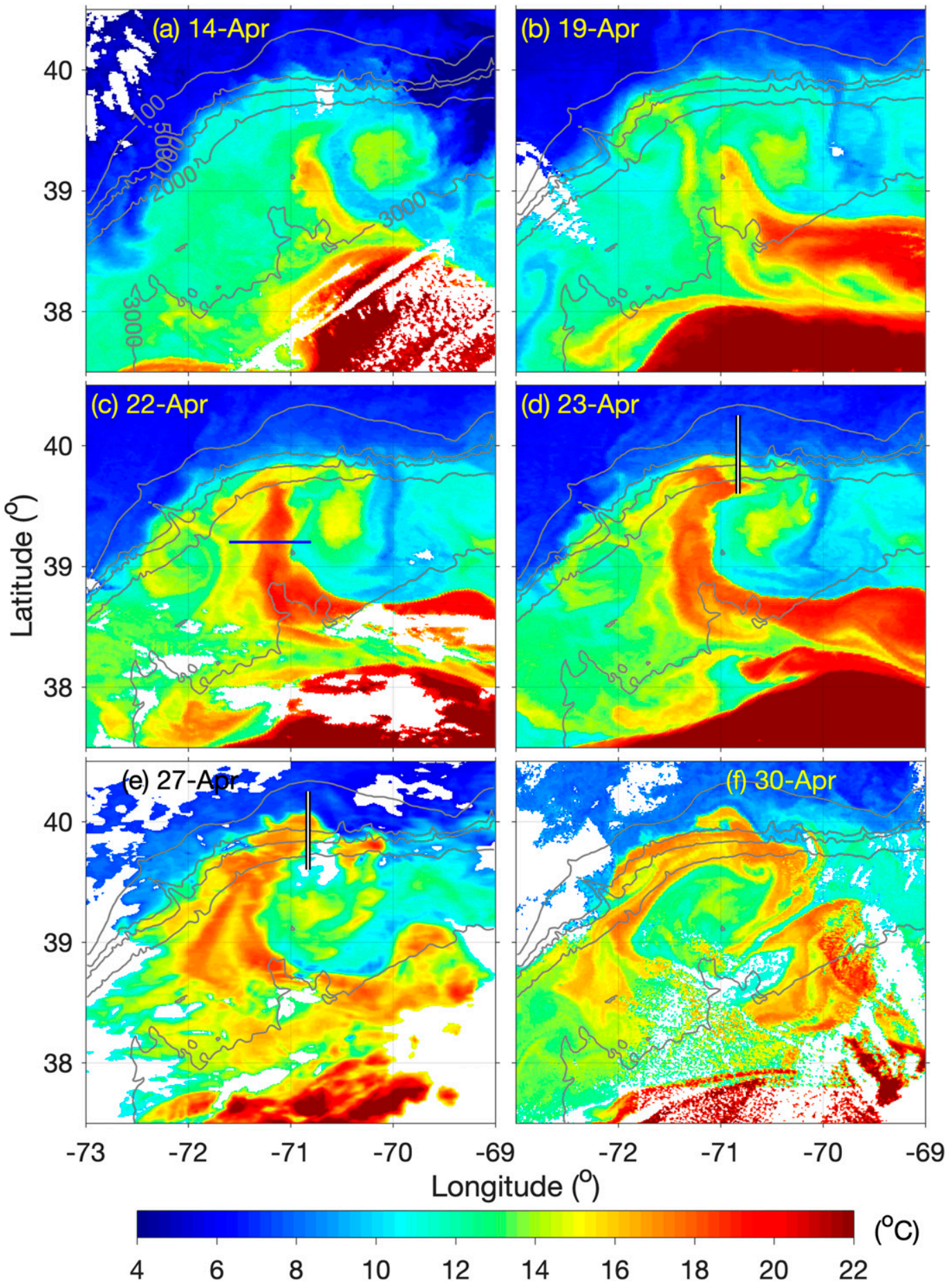

FIG. 3. (a)-(f) Images of satellite-measured sea surface temperature showing the development and evolution of a warm spiral streamer during the AR29 expedition in April 2018. The vertical white lines in (d) and (e) respectively indicate the locations of the cross-shelf CTD and VPR transects shown in Fig. 4 below; the horizontal blue line in (c) shows a radial section to the west of the ring (to help with the explanation in the text) where the warm streamer is not in contact with the shelf water yet. The white areas are cloud cover. 

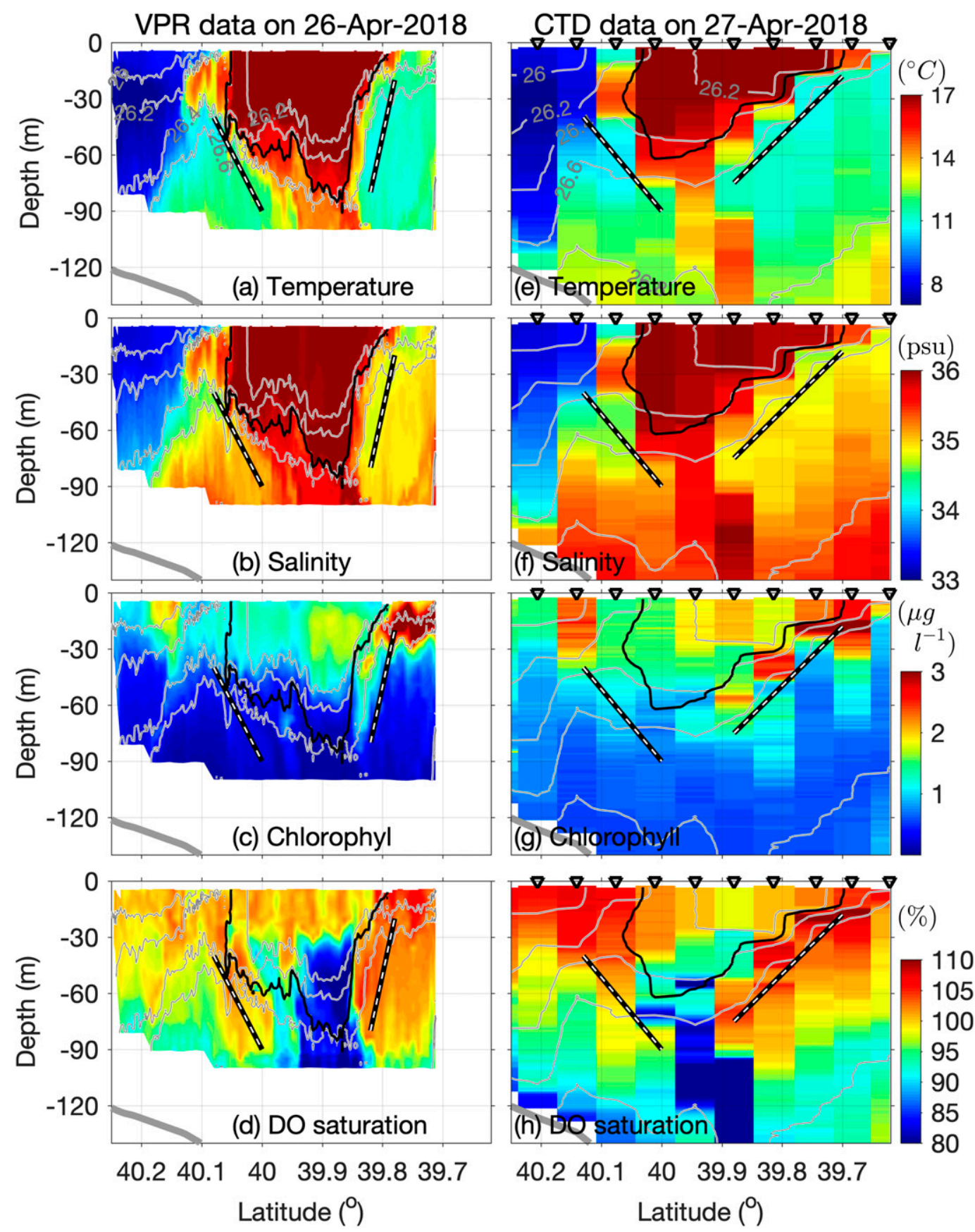

FIG. 4. Cross-shelf distribution of (top) temperature, (top middle) salinity, (bottom middle) chlorophyll concentration, and (bottom) oxygen saturation measured by (a)-(d) a towed VPR and (e)-(h) shipboard CTD in April 2018. Thin gray lines are isopycnal contours with the interval of $0.2 \mathrm{~kg} \mathrm{~m}^{-3}$; Thick gray lines are the bottom; thick black lines are isothermal contours of $15.5^{\circ} \mathrm{C}$ indicating the boundary of the warm streamer lens; the black-white dashed lines highlight the subduction signal on both sides of the warm streamer lens.

The simulations are run for 30-60 days. Three passive tracers, representing the ring, surface ring, and eddy waters with concentration $C_{r}, C_{\mathrm{rs}}$, and $C_{e}$, respectively, are included in the model to simulate evolution of the water masses (Fig. 6). The initial value of $C_{r}$ is 1 in the ring and 0 elsewhere; the initial value of $C_{\mathrm{rs}}$ is 1 in the top $30 \mathrm{~m}$ of the ring and 0 elsewhere; the initial value of $C_{e}$ is 1 in the eddy and 0 elsewhere.

To analyze the dynamics of eddy water intrusion, part of the model field and terms of momentum balance will be presented in the cylindrical coordinates with the origin at the ring center, 


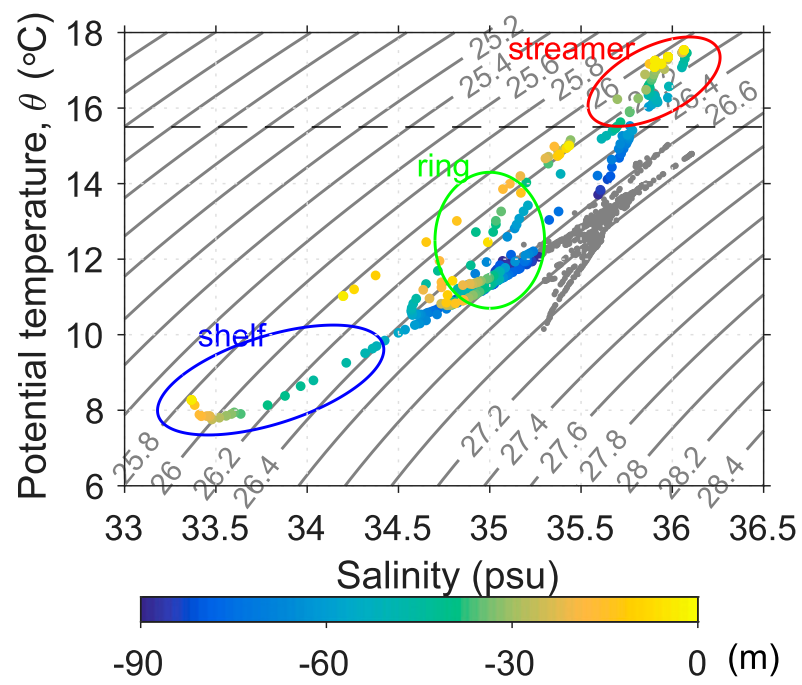

FIG. 5. Temperature-salinity diagram of the shipboard CTD data on 27 Apr 2018. Depths of the data in the top $90 \mathrm{~m}$ are colored. The blue, green, and red ovals highlight the shelf, ring, and warmstreamer waters, respectively.

the radial coordinate $r$, pointing outward from the ring center, and the azimuthal angular coordinate $\theta$, pointing counterclockwise. The radial momentum equation in the cylindrical coordinates is

$$
\begin{aligned}
\underbrace{\frac{\partial u_{r}}{\partial t}}_{\text {acceleration }}= & \underbrace{-u_{r} \frac{\partial u_{r}}{\partial r}-\frac{u_{\theta}}{r} \frac{\partial u_{r}}{\partial \theta}+\frac{u_{\theta}^{2}}{r}}_{\text {horizontal advection }} \underbrace{-w \frac{\partial u_{r}}{\partial z}}_{\text {vertical advection Coriolis }} \underbrace{+f u_{\theta}}_{\text {horizontal mixing }} \\
& \underbrace{-\frac{1}{\rho_{o}} \frac{\partial p}{\partial r}}_{\text {pressure gradient }} \underbrace{\nu_{h}\left[\frac{1}{r} \frac{\partial}{\partial r}\left(r \frac{\partial u_{r}}{\partial r}\right)-\frac{u_{r}}{r^{2}}+\frac{1}{r^{2}} \frac{\partial^{2} u_{r}}{\partial \theta^{2}}-\frac{2}{r^{2}} \frac{\left.\partial u_{\theta}\right]}{\partial \theta}\right]}_{\text {vertical mixing }}
\end{aligned}
$$

Here, $u_{r}, u_{\theta}$, and $w$ are the radial, azimuthal, and vertical velocity, respectively; $p$ is pressure; $\rho_{o}$ is reference density; and $\nu_{h}$ and $\nu_{v}$ are horizontal and vertical viscosity, respectively.

\section{Results}

\section{a. Observations}

Satellite images of SST in Fig. 1 show warm spiral streamers in old WCRs at different times. Most of the spiral streamers are connected to the Gulf Stream to the south, except the one on 11 November 2012 (Fig. 1c) which stems from a newly formed WCR to the west. In all cases, the surface temperature of the old rings prior to the spiral formation is lower than the surface temperature of the sources of the warm streamers (not shown). Despite differences in the details, the spiral streamers show a common feature of a gradual radial shift of the warm streamers toward the ring centers as the streamers wind anticyclonically

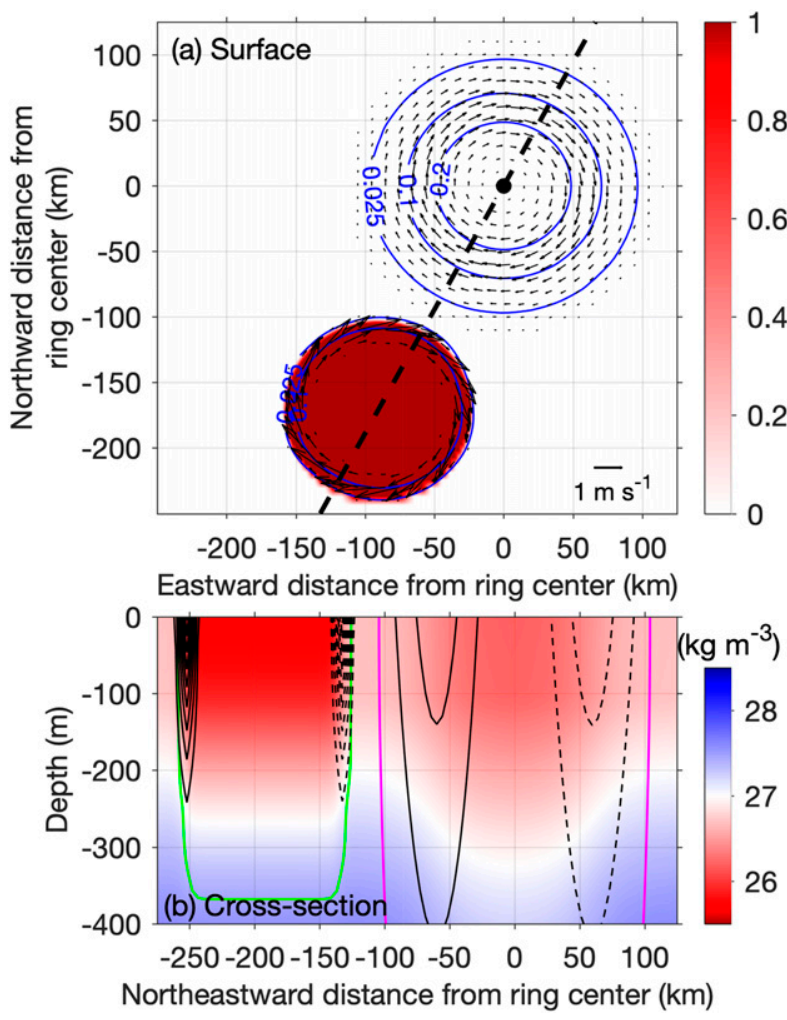

FIG. 6. (a) Top and (b) cross-sectional views of the initial conditions of the control model. In (a), color indicates surface concentration of the buoyant eddy water $C_{e}$, blue lines are contours of sea surface height $(\mathrm{m})$, arrows are surface velocity with the scale at the lower-right corner, and the black dashed line indicates the location of the cross section in (b). In (b), the colors indicate the potential density $\sigma_{\theta}$, solid and dashed black lines are contours of northwestward and southeastward velocity, respectively, with the interval of $0.2 \mathrm{~m} \mathrm{~s}^{-1}$, the green line indicates the boundary of the eddy water $\left(C_{e}=0.5\right)$, and the magenta line indicates the boundary of the ring water $\left(C_{r}=0.5\right)$. Note that the vertical and horizontal extent of the panels here are much greater than that of a warm spiral streamer.

into the rings. The radial shift of the streamers results in a radial offset between the nose and tail of the streamer when the nose completes a cycle around the ring and is an essential characteristic of the spiral formation. Without it, the nose of a streamer would merge with its tail and form a closed loop around the old ring, as depicted by Nof (1986). The inward radial motion of the spiral streamers is a key point of this study and will be discussed in the following sections.

SST images in June 2012 show temporal evolution of a spiral streamer (Fig. 2). On 10 June, a WCR that was formed 2 months earlier (not shown) had moved to the slope region around $41^{\circ} \mathrm{N}, 65^{\circ} \mathrm{W}$, and its surface temperature had dropped from an initial value of $\sim 25^{\circ}$ to $\sim 20^{\circ} \mathrm{C}$, presumably due to heat loss to the atmosphere. Meanwhile, a distinct cold shelf-water filament had formed on the eastern flank of the ring, and a northwestward-extending meander wave of the Gulf Stream with surface temperature of $25^{\circ} \mathrm{C}$ had come into direct contact 
TABLE 1. Model runs and parameters that differentiate them.

\begin{tabular}{lcccc}
\hline \multicolumn{1}{c}{ Run name } & $\begin{array}{c}\left(x_{0, e}, y_{0, e}\right)(\mathrm{km}) \\
\text { (eddy center } \\
\text { coordinate) }\end{array}$ & $\begin{array}{c}\Delta \rho_{0, e}\left(\mathrm{~kg} \mathrm{~m}^{-3}\right) \\
(\text { eddy surface } \\
\text { density anomaly) }\end{array}$ & $\begin{array}{c}H_{e}(\mathrm{~m}) \\
\text { (eddy depth scale) }\end{array}$ & $\begin{array}{c}\beta[(\mathrm{m} \mathrm{s}) \\
\text { (meridional gradient } \\
\text { of Coriolis parameter) }\end{array}$ \\
\hline Control Run & $(-90,-170)$ & -1 & 150 & 0 \\
Low Density Anomaly (LDA) Run 1 & $(-90,-170)$ & -0.5 & 150 & 0 \\
Low Density Anomaly (LDA) Run 2 & $(-90,-170)$ & -0.125 & 150 & 0 \\
Beta Run & $(-90,-170)$ & -0.125 & 150 & 0 \\
Subduction (SBD) Run 1 & $(-100,-100)$ & -1 & 60 & 0 \\
Subduction (SBD) Run 2 & $(-100,-100)$ & 0 & 60 & 0 \\
\hline
\end{tabular}

with the ring on its southern flank. On 12 June, the Gulf Stream meander had largely separated from the Gulf Stream, forming an eddy with a radius smaller than the width of the Gulf Stream. Therefore, it is likely a buoyant eddy with a shallower vertical extent than the WCR. There was a thin filament of warm water connecting the eddy back to Gulf Stream. At the same time, water on the northern side of the warm meander eddy had been pulled farther northward by the ring forming a sharp pinnacle (Fig. 2b). In the following days, the warm pinnacle extended laterally forming a filament, and much of the warm water in the eddy-like feature was gradually pulled into the ring. Over time, the warm water rolled up around the ring completing two circles, forming a warm spiral streamer. This spiral formation event, to some extent, also resembles the process of vortex merging (von Hardenberg et al. 2000), which will be discussed in section 4 .

A warm spiral streamer with a less pronounced surface pattern formed in the slope region south of New England in April 2018 during the AR29 expedition (Fig. 3). In the beginning of April 2018, a WCR that had separated from the Gulf Stream in November 2017 came into contact with the shelf edge and generated a distinct cold shelf-water streamer. On 14 April, the surface temperature at the center of the ring was $11^{\circ}-14^{\circ} \mathrm{C}$, much lower than its initial value of $\sim 25^{\circ} \mathrm{C}$ in November 2017. The ring had thus lost much of its surface buoyancy. On 14 April, the ring encountered a northwardextending Gulf Stream wave crest to the south. On 19 April, a filament of warm Gulf Stream water started to be entrained by the ring and moved northwestward along the ring periphery. The nose of the warm filament resided between the slope water to its west and ring water to its east. In the next two weeks, the warm filament moved anticyclonically over the ring forming a spiral streamer.

The AR29 expedition captured the subsurface structure of the warm spiral streamer and provides an unprecedented opportunity to study its dynamics. Data from the VPR and CTD depict the streamer on the northern flank of the ring as a nearsurface warm and saline feature with the maximum thickness of $60-80 \mathrm{~m}$, bounded by the $15.5^{\circ} \mathrm{C}$ isotherm (Fig. 4). Because of the high cross-shelf resolution of the VPR tow, VPR data show finescale variability along the boundary of the streamer. In contrast, the CTD data miss the finescale variability because of the low cross-shelf resolution.

Density of the water in the warm streamer is 1026$1026.2 \mathrm{~kg} \mathrm{~m}^{-3}$, similar to the cold and fresh shelf water to the north and lower than the ring water to the south with intermediate temperature and salinity (Fig. 5). Consequently, VPR data show a clear density front with closely spaced isopycnals extending over the depth range of $20-90 \mathrm{~m}$ on the southern (interior) wall of the warm streamer; the density front on the northern (exterior) wall of the warm streamer is weaker and extends over a smaller depth range of 50-70 m (Figs. 4a-d). Because the streamer water has a density similar to the shelf water, and previous studies have shown that MAB shelf water is less dense than the slope water offshore (e.g., Houghton et al. 2009; Linder and Gawarkiewicz 1998), the warm streamer water here is thus less dense than the background slope water outside of the ring. On any radial section to the west of the ring where the warm streamer is not in contact with shelf water (e.g., the blue line in Fig. 3c), water in the warm streamer is less dense than both the slope water to its west (exterior side) and the water to its east (interior side). Thus, there should be density fronts on both the exterior and interior sides of the warm streamer. This cross-streamer density distribution has important dynamical implications (see below).

VPR and CTD data also show subsurface slanted layers of intermediate temperature $\left(11^{\circ}-12^{\circ} \mathrm{C}\right)$, intermediate salinity (34.8-35 psu), high chlorophyll (1.5-3 $\left.\mu \mathrm{g} \mathrm{L}^{-1}\right)$, and high oxygen waters $(>98 \%)$ on both exterior and interior sides of the warm streamer (as highlighted by the black-white dashed lines in Fig. 4). The slanted layer on the interior side (to the right in Fig. 4) is about $50 \mathrm{~m}$ thick with a diffuse lower boundary. It is visible in all variables, and its slope aligns mostly with the isopycnals. High concentrations of dissolved oxygen and chlorophyll suggest that water in the slanted layer originated from the surface mixed layer. At the top of the slanted layer, VPR data show a continuous layer of high chlorophyll concentration, while the area of high chlorophyll measured with the CTD is separated into discrete patches. The separation between the high chlorophyll patches in the CTD data is an artifact of the low cross-shelf resolution of the CTD profiles and reflects the fact that the vertical offset of subsurface chlorophyll maximum at neighboring CTD profiles is larger than the thickness of the high chlorophyll layer. This artifact does not affect the interpretation of the subsurface pattern of the warm spiral and the associated slanted layers, as they are clearly shown in the VPR data. Temperature in the interior slanted layer is consistent with the surface temperature of the ring water on the interior side of the warm streamer (Figs. 2d,e, 3d,e). Water in the interior slanted layer thus originates 
from the surface ring water on the interior side of the warm streamer.

The slanted layer on the exterior side of the warm streamer (to the left in Fig. 4) is visible in the oxygen distribution, as evidenced by the thick layer of elevated oxygen concentrations extending from the surface downward to about $90 \mathrm{~m}$. The slope of this slanted layer does not completely align with the isopycnals. Both salinity and oxygen concentration of the exterior slanted layer indicate that it originates from the surface slope water. First, the high oxygen concentration indicates that water in the subsurface slanted layer originates from the surface mixed layer. Second, salinity in that layer is $\sim 35 \mathrm{psu}$, consistent with the characteristic salinity of the slope water near the shelf edge, and distinctively different from the characteristic low salinity of the shelf water $(<34.5 \mathrm{psu})$ and the high salinity of the ring water ( $>36 \mathrm{psu}$ ) in the region (Linder and Gawarkiewicz 1998; Zhang and Gawarkiewicz 2015). Note that because of the strong density compensation effect of temperature and salinity variations (i.e., the spiciness) in the shelf break region (Todd et al. 2013), potential density is not a good indicator of the source of the water in the exterior slanted layer. The observed low temperature and low salinity inshore of $40.1^{\circ} \mathrm{N}$ (Figs. $4 \mathrm{~b}, \mathrm{f}$ ) represent characteristic properties of the shelf water in the region (Linder and Gawarkiewicz 1998), and they differ significantly from the water properties in the exterior slanted layer.

The observed pattern of subsurface slanted layers on both sides of the warm streamer appears to be consistent with the pattern of frontal subduction at an intensifying density front (e.g., Mahadevan and Tandon 2006; Spall 1995). Meanwhile, the direction of the flow in the subducting layers is opposite to the double-sided frontal upwelling at cold dense filaments in the Gulf Stream (Gula et al. 2014). As a density front intensifies due to a background convergent flow or lateral stretching, i.e., frontogenesis, an ageostrophic secondary cross-sectional flow that tends to relax the intensifying front is formed (McWilliams et al. 2009). Frontal subduction is a component of the ageostrophic secondary cross-sectional flow. It occurs on the higher-density side of the front and tends to move surface water from the higher-density side downward along isopycnals toward the lower-density side of the front (see Fig. 3 in Spall 1995). In contrast, Gula et al. (2014) showed that when a cold dense filament in the Gulf Stream is stretched, fronts on both sides of the cold filament is intensified, and a double-cell frontal secondary flow with upwelling on the outer edges and subduction in the middle is formed (see Fig. 6 in Gula et al. 2014). The slanted subducting layers on both sides of the warm streamer that we observed in the WCR appears to be flowing in the opposite directions as to the upwelling on the outer edges of the double-cell secondary flow described by Gula et al. (2014). Zhang and Partida (2018) demonstrated that the frontal secondary flow and the associated frontal subduction can occur at the edge of a WCR to counterbalance the intensifying ring-edge front.

The observed density front on the interior side of the warmer streamer is consistent with frontogenesis. The less pronounced density front on the exterior side could result from the streamer exterior edge contacting the low-density shelf water to the north. When the warm streamer water was on the western side of the ring before moving into the sampling region in the north, frontogenesis and associated subduction of surface slope water could have occurred on its exterior (western) side. As the warm streamer water, together with the subducted slope water, moved clockwise to the northern side of the ring, meeting the low-temperature, low-salinity, and low-density shelf water on the surface, isopycnals in the near-surface region of the exterior front could merge with the shelf water isopycnals. Consequently, the surface part of the exterior front and the associated subduction signal could be diminished, while the subsurface part in the depth range of $50-70 \mathrm{~m}$ remained. This is consistent with the water in the exterior slanted layer being surface slope water, and could also potentially explain the subduction signal on the exterior side of the warm streamer being less pronounced in temperature and salinity. Meanwhile, the cross-isopycnal appearance of the exterior slanted layer could result from lateral straining (Smith and Ferrari 2009) of the water subducted over a broad isopycnal range, which could occur at the edge of a WCR (Zhang and Partida 2018).

Despite this depiction of the vertical structure of the warm spiral streamer, the observations are insufficient for a direct analysis of its formation mechanism. For that, we examine model simulations that are designed to mimic the observed density variation among the different water masses.

\section{b. Modeling of the spiral pattern}

The control simulation reproduces the basic pattern of the warm spiral streamer over the WCR (Fig. 7). In particular, as time proceeds, instability develops on the periphery of the buoyant eddy and gradually evolves into large-amplitude meanders. On day 13, a limb of the buoyant eddy reaches the edge of the WCR, as indicated by the SSH contour of $0.025 \mathrm{~m}$ of the eddy merging with that of the ring. In the next few days, the eddy limb starts to intrude farther toward the center of the ring and then moves anticyclonically around the eddy. On day 17, the nose of the eddy water filament has been stretched and reaches the $0.1 \mathrm{~m} \mathrm{SSH}$ contour of the ring. On day 29, the nose of the filament has completed a cycle around the ring reaching the $0.2 \mathrm{~m} \mathrm{SSH}$ contour of the ring. Meanwhile, there is an offset between the nose and the tail of the filament in the radial direction, resulting from a net radial intrusion of the nose toward the center of the ring. The radial intrusion and the winding motion of the filament nose together give rise to the spiral streamer pattern of the eddy water filament into the WCR. Similar to some of the warm spiral streamers on the satellite images (e.g., Fig. 3f), the modeled spiral streamer meanders along its azimuthal path, and its cross-stream width varies as well. After day 29, instability on the WCR periphery develops and gradually breaks down the spiral pattern (not shown). Note that the time it takes the modeled spiral streamer to develop from the first contact on day 13 is qualitatively consistent with the event in June 2012 (Fig. 2).

A cross section of the eddy passive tracer on the northern side of the ring on day 23 (Fig. 8) resembles the warm streamer cross section captured by VPR and CTD. It is a surface lens about $80 \mathrm{~m}$ thick residing between the intermediate-density ring water on its interior side (the right side in Fig. 8) and higher-density water on its exterior side (the left side in Fig. 8). 

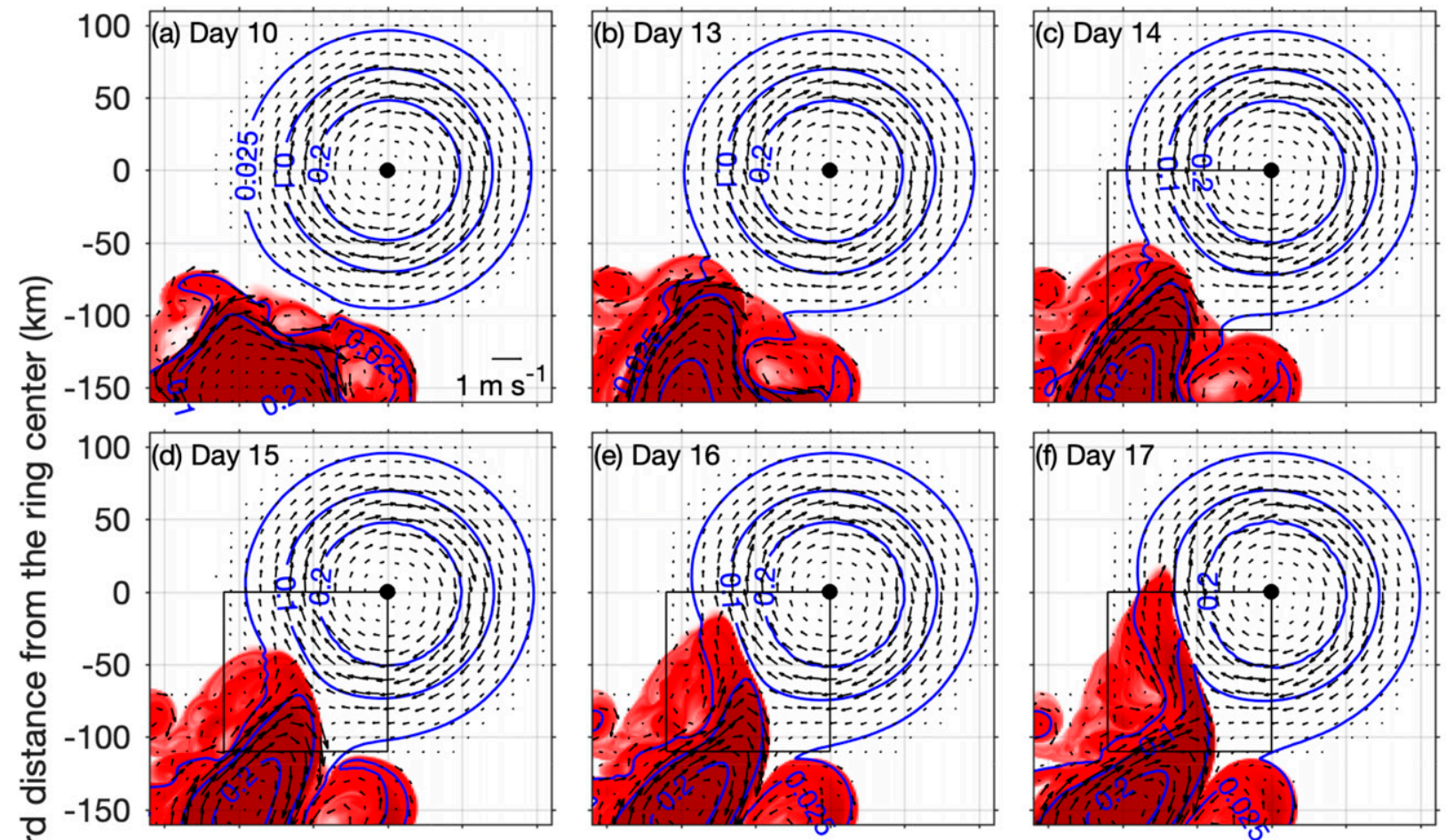

을

50
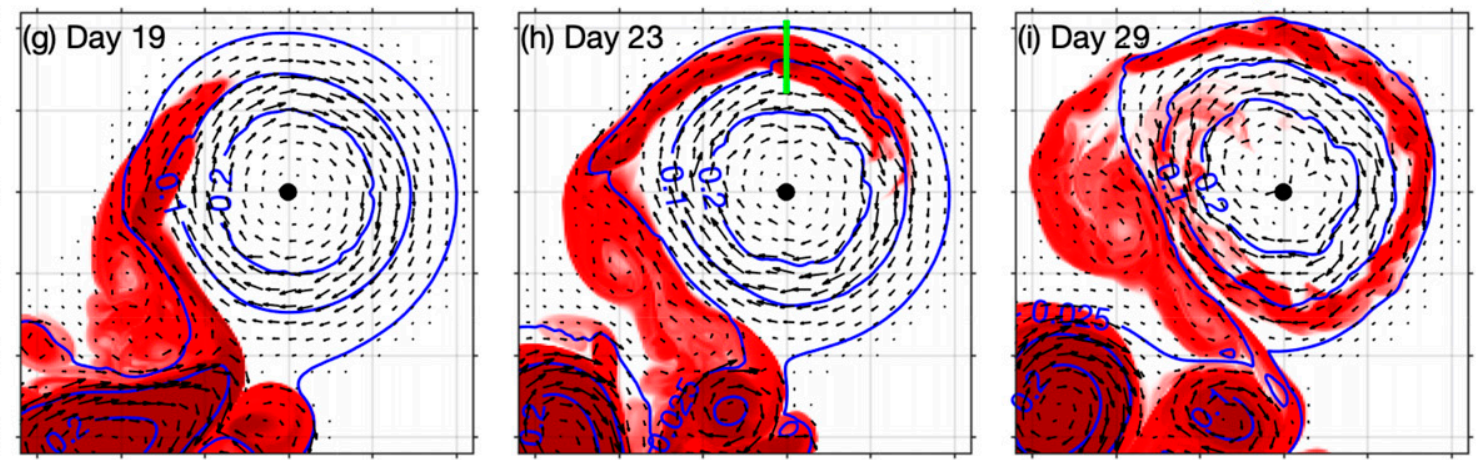

$-150$

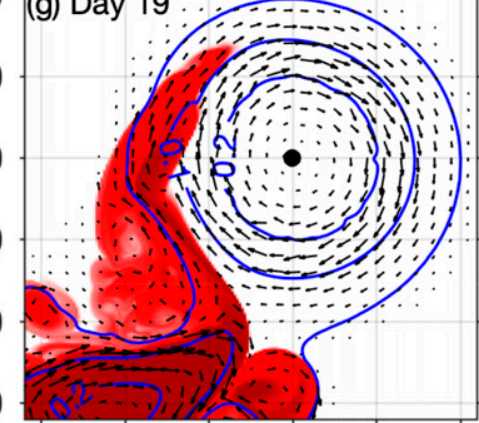

$-150-100-50$

0

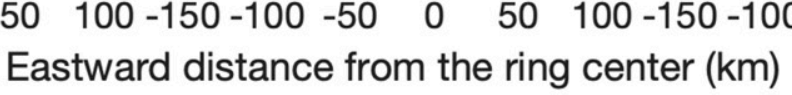

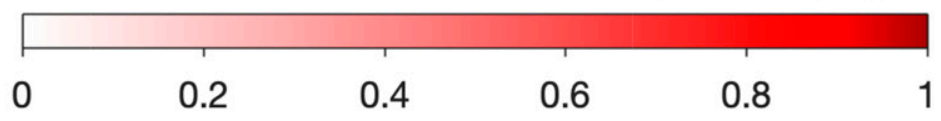

FIG. 7. Snapshots of sea surface height (blue contours), surface velocity (arrows), and surface concentration of buoyant eddy water $C_{e}$ (colors) from the Control Run. A scale of the velocity is provided at the lower-right corner of (a). The vertical green line in (h) indicates the location of the cross section shown in Fig. 8, below; the black boxes in (c)-(f) give the field of view in Fig. 9, below; the black dots represent the initial ring center.

Note that, by design, the model does not have shelf water on the exterior side of the streamer. The modeled velocity on day 23 indicates that flow on the entire cross section is eastward with the maximum speed of $0.75 \mathrm{~m} \mathrm{~s}^{-1}$ (Fig. 8b), consistent with the anticyclonic ring flow. The north-south velocity on the cross section is inhomogeneous and much weaker with speed generally less than $0.1 \mathrm{~m} \mathrm{~s}^{-1}$ (Fig. 8c).

To investigate the dynamics of the simulated warm water streamer, in particular, the radial motion of the intruding buoyant eddy water toward the ring center, we zoom into the eddy-ring contact region during the onset of the streamer radial intrusion, and examine the density and relative vorticity field and associated momentum balance at the nose of the eddy-water intrusion. The evolution of the sea surface density during days 14-17 (Fig. 9) shows a strong density gradient at the eddy-ring interface and a local anticyclonic flow inside the eddy-water nose at the beginning of the interaction. Subsequently, there is a clear radial motion of the eddy-ring interface toward the 


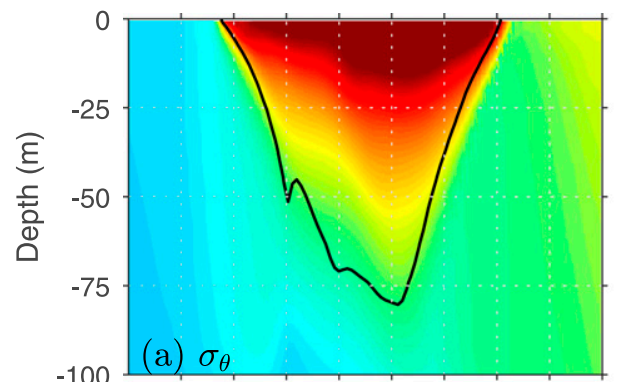

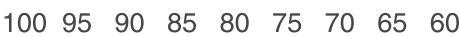

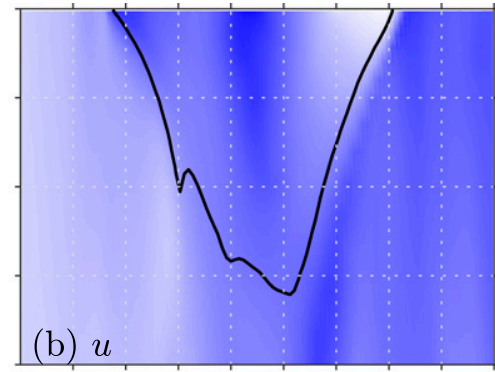

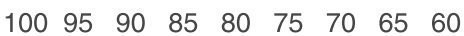

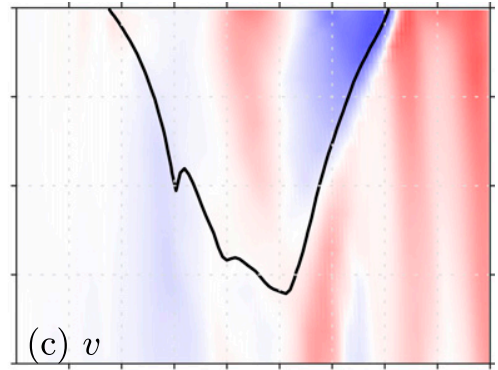

$\begin{array}{lllllllll}100 & 95 & 90 & 85 & 80 & 75 & 70 & 65 & 60\end{array}$ Northward distance from the ring center $(\mathrm{km})$

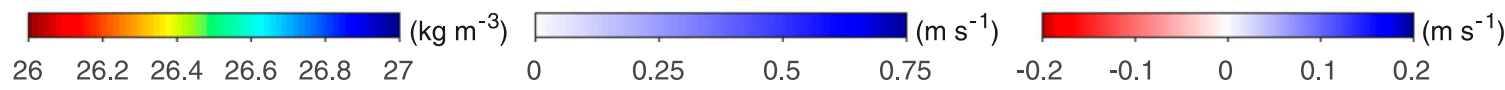

FIG. 8. Cross-sectional distribution of (a) $\sigma_{\theta}$, (b) eastward velocity, and (c) northward velocity along the green line in Fig. $7 \mathrm{~h}$ on day 23 from the Control Run. The black lines show the boundary of the eddy water streamer as indicated by the eddy passive tracer concentration of 0.5 . Note that this is a zoomed-in view of the cross-section of the streamer and that the vertical and lateral extents of the panels here are much smaller than in Fig. 6 b.

ring center. The eddy-ring interface barely crosses the ring arc of 84.5-km radius (black dashed line in Fig. 9a) on day 14, and at day 15 the sharp interface is $\sim 15 \mathrm{~km}$ inward of the arc. In the next two days, the sharp interface moves farther toward the ring center. On day 14 , the buoyant eddy water on the along-arc vertical section shows a lens shape of about $15 \mathrm{~m}$ thick (Figs. 10b-d); the radial velocity $u_{r}$ in the lens is mostly negative toward the ring center, and the maximum radial speed is at the right edge of the lens (looking from the ring center); tangential velocity $u_{\theta}$ inside the lens is mostly positive (counterclockwise), corresponding to the local anticyclonic flow inside the nose. The tangential velocity away from the lens is mostly negative (clockwise), consistent with the large-scale anticyclonic ring flow.

The radial momentum balance along the arc indicates that the radial pressure gradient force and momentum advection, both pointing toward the center of the WCR, together drive a radial acceleration of the buoyant eddy water. The flow along the arc section is to lowest-order geostrophic with Coriolis and pressure gradient forces largely balancing each other in most of the section (Figs. 10e,f). Within the buoyant eddy water lens (as highlighted by the black contour), the Coriolis force points away from the ring center (into the page), and the pressure gradient force points toward the ring center (out of the page). Outside of the buoyant eddy water, the Coriolis and pressure gradient forces switch directions, consistent with the local eddy-ring interfacial flow opposing the background flow of the WCR. The Rossby number of the flow on the eddy-ring interface $\mathrm{Ro}=U /(f L) \sim 0.2$, based on a flow speed $U \approx 0.5 \mathrm{~m} \mathrm{~s}^{-1}$ and a length scale $L \approx 20 \mathrm{~km}$. The residual of Coriolis and pressure gradient forces (Fig. $10 \mathrm{~g}$ ) points toward the ring center (out of the page) in a band to the lower right of the lens, driven by an excess in the pressure gradient force. The horizontal momentum advection (Fig. 10h) mostly points toward the ring center (out of the page). Note that (i) the eddy-ring interface bends toward the ring center (black solid line in Fig. 9a); (ii) the local flow in the nose of the intruding streamer is anticyclonic along the interface, embedded within the largescale anticyclonic flow of the WCR. The horizontal momentum advection inside the buoyant eddy water lens thus point toward the ring center, corresponding to the centrifugal force of the local anticyclonic flow in the nose of the streamer that tends to push the eddy water toward the ring center (outward from the buoyant eddy). Because the weaker horizontal velocity in the thin layer below the buoyant eddy water lens is anticyclonic (mostly following the eddy-ring interface), the horizontal momentum advection to the lower right of the lens also points toward the ring center, reinforcing the pressure gradient force there (Fig. 10g). Consistently, the acceleration term shows a strong negative pattern in a band to the lower right of the lens (Fig. 10j), corresponding to the inward intrusion of the eddy water on the northern edge of the nose (right side of the lens looking from the ring center). It is this inward intrusion of the nose of the buoyant eddy water that, combined with its clockwise winding motion driven by the large-scale ring flow, causes the radial offset between the nose and the tail, and forms the spiral pattern on day 29 (Fig. 7). Note that the importance of momentum advection in the radial momentum balance is consistent with the finite amplitude Ro of the frontal flow.

The density difference between the eddy and ring waters is a key driver of the radial intrusion of the eddy water and spiral streamer formation. It causes a horizontal density gradient across the eddy-ring interface and a downward tilt in sea level from the eddy toward the ring (Fig. 10a), i.e., a pressure gradient force pointing toward the ring center. Because the flow at the eddy-ring interface is thermal-wind balanced to first order, the cross-interface horizontal density gradient drives a vertical shear of the horizontal velocity. This results in a local anticyclonic along-interface flow in the nose of the intruding buoyant eddy water, opposite in direction to the large-scale flow of the WCR at the location (Fig. 9). The associated local momentum advection, together with the pressure gradient force associated with the cross-interface sea level tilt, drive radial intrusion of the buoyant eddy water toward the ring center.

To demonstrate the key role of the eddy-ring density difference in forming the spiral streamer, we examine sensitivity 


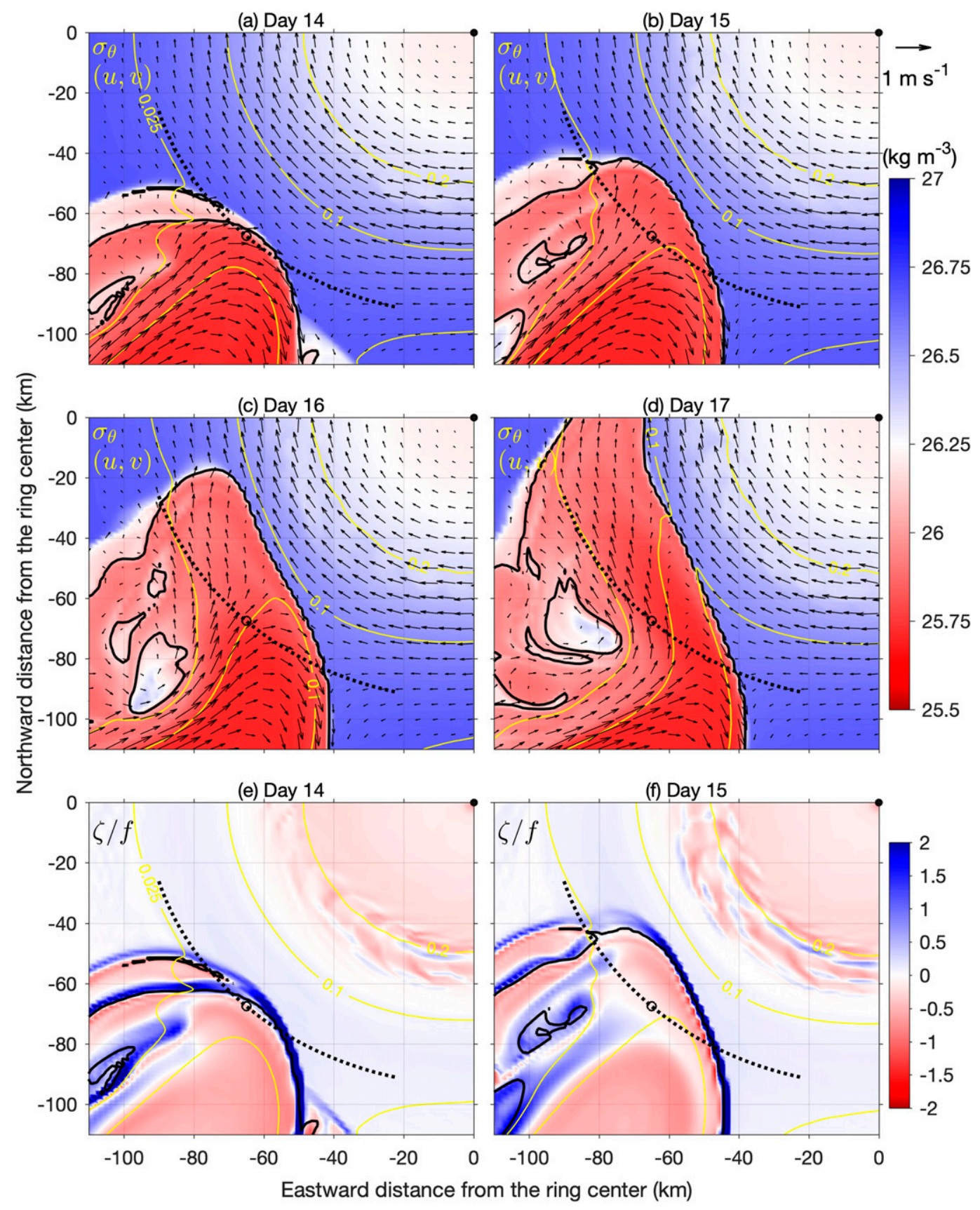

FIG. 9. A zoomed-in view of (a)-(d) sea surface density (colors), height (yellow lines), and velocity (arrows) and (e),f) surface relative vorticity normalized by Coriolis at different times showing the initial development of the eddy-water streamer in the Control Run. The black solid lines indicate the boundary of the buoyant eddy water on the surface; the black dashed line is an arc along which the model field is shown in Fig. 10; the arc is centered on the ring center and has a radius of $84.5 \mathrm{~km}$; the circle is the middle point of the arc.

simulations with $\Delta \rho_{0, e}=-0.5$ (LDA Run 1; Figs. 11a-c) and $-0.125 \mathrm{~kg} \mathrm{~m}^{-3}$ (LDA Run 2; Figs. 11d-f), both having weaker eddy-water density anomalies than the Control Run $\left(\Delta \rho_{0, e}=-1\right)$. As the time scale of the nonlinear eddy-ring interaction increases with decreasing $\Delta \rho_{0, e}$, we examine results of the sensitivity simulations over time periods longer than that of the control simulation and before the ring is severely deformed or moves too far away from its initial position. LDA Run 1 (Figs. 11a-c) shows meander development along the eddy periphery, outward extension of the eddy water, and an initial intrusion of eddy water toward the WCR, all similar to the control case. However, the intruding eddy water is 

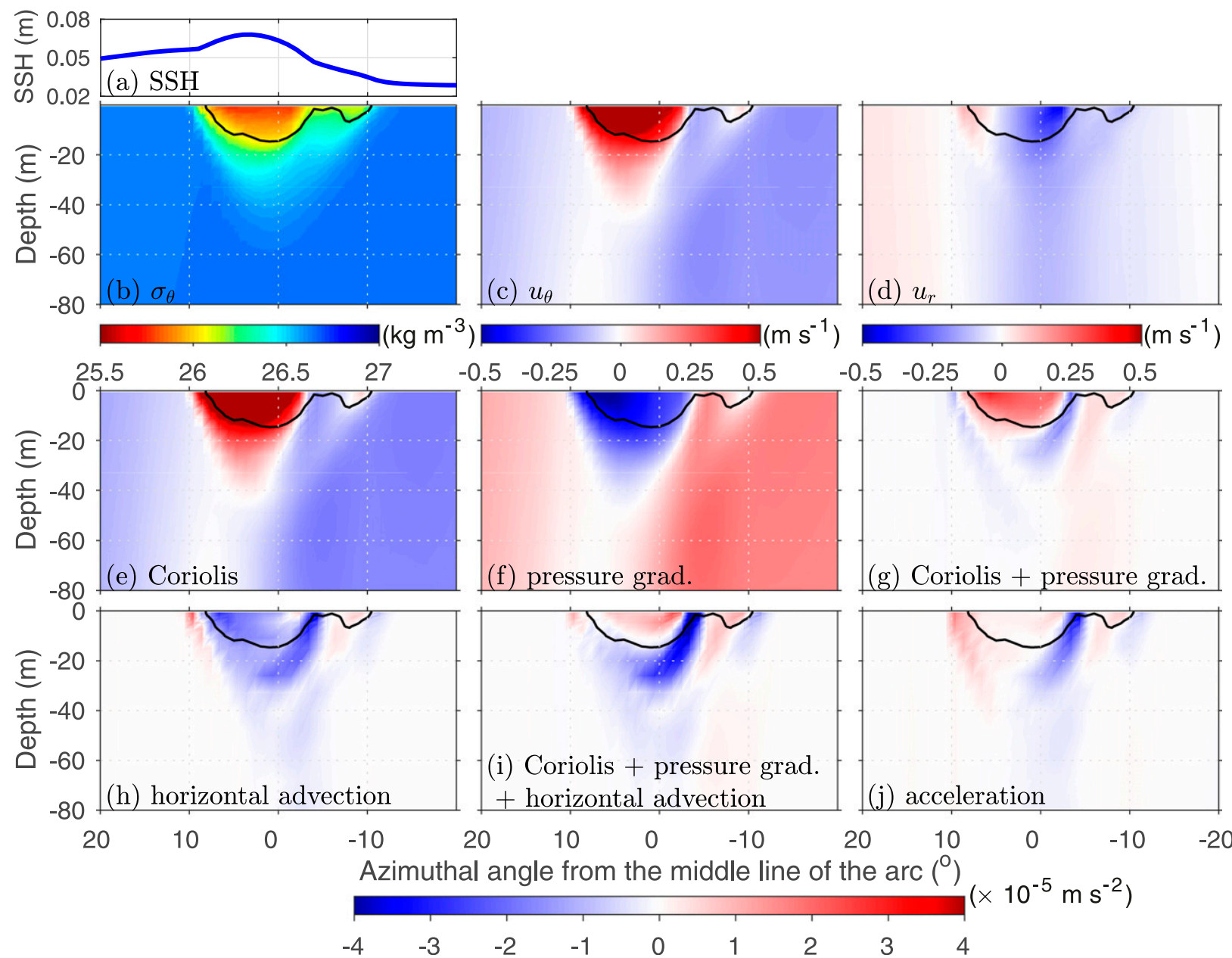

FIG. 10. Along-arc distribution of (a) SSH, (b) $\sigma_{\theta}$, (c) tangential velocity, and (d) radial velocity, along with major terms of the radial momentum balance (dashed line in Fig. 9a) at the onset of the eddy water spiral streamer (day 14) from the Control Run. The major terms of the radial momentum balance shown are (e) Coriolis, (f) pressure gradient, (g) sum of Coriolis and pressure gradient, (h) horizontal advection, (i) sum of Coriolis, pressure gradient and horizontal advection, and (j) acceleration. Other terms in the momentum balance are negligible and are not shown here. Black lines indicate the edge of the buoyant eddy streamer water. The $x$ axis is the azimuthal angle relative to the middle line of the arc; the positive azimuthal direction is defined as counterclockwise, and the positive radial direction is defined as outward away from the ring center. The panels are viewed from the prospective of the eddy center.

substantially diluted, and the intrusion stops at the outskirt of the ring with no further inward motion toward the ring center. On day 23, some eddy water crosses the $0.025-\mathrm{m} \mathrm{SSH}$ contour of the ring and is carried northward along the SSH contour with no tendency to move closer toward the ring center (Fig. 11b). Close examination shows that the density difference between the eddy water and the surrounding ring water at this time is $<$ $0.1 \mathrm{~kg} \mathrm{~m}^{-3}$, and the eddy water acts as a passive tracer being moved around by the underlying ring current. By day 40, a thin surface layer (thickness $<20 \mathrm{~m})$ of diluted eddy water $\left(C_{e}<\right.$ 0.2 ) is scattered around the $0.025-\mathrm{m} \mathrm{SSH}$ contour of the ring with no clear spiral pattern (Fig. 11c). A similar pattern occurs in LDA Run 2 with no radial intrusion of the ring water or spiral streamer (Figs. 11d-f).

In the real ocean, WCRs migrate laterally in the Slope Sea due to the $\beta$ effect, and sometimes impinge on younger rings or the Gulf Stream. To examine whether this type of lateral migration of the WCR could facilitate formation of a spiral streamer, a run with $\beta=1.76 \times 10^{-11}(\mathrm{~m} \mathrm{~s})^{-1}\left(40^{\circ} \mathrm{N}\right)$ and $\Delta \rho_{0, e}=-0.125 \mathrm{~kg} \mathrm{~m}^{-3}$ was carried out. Its comparison with LDA Run 2 reveals that lateral migration of the ring does not form the spiral when the other spiral formation mechanism is absent. As a result of nonlinear Rossby wave propagation on the $\beta$ plane (Early et al. 2011; McWilliams and Flierl 1979), the modeled WCR migrates to the southwest against the buoyant eddy (Figs. 11g-i). Initial entrainment of the eddy water into the ring is enhanced by ring impingement. However, the eddy water stays on the periphery of the ring without moving closer to the ring center. As the ring continues migrating southwestward and deforms due to instability, it pushes the eddy aside.

Lack of radial intrusion of the eddy water in the WCR in the sensitivity simulations confirms that negative density anomaly 

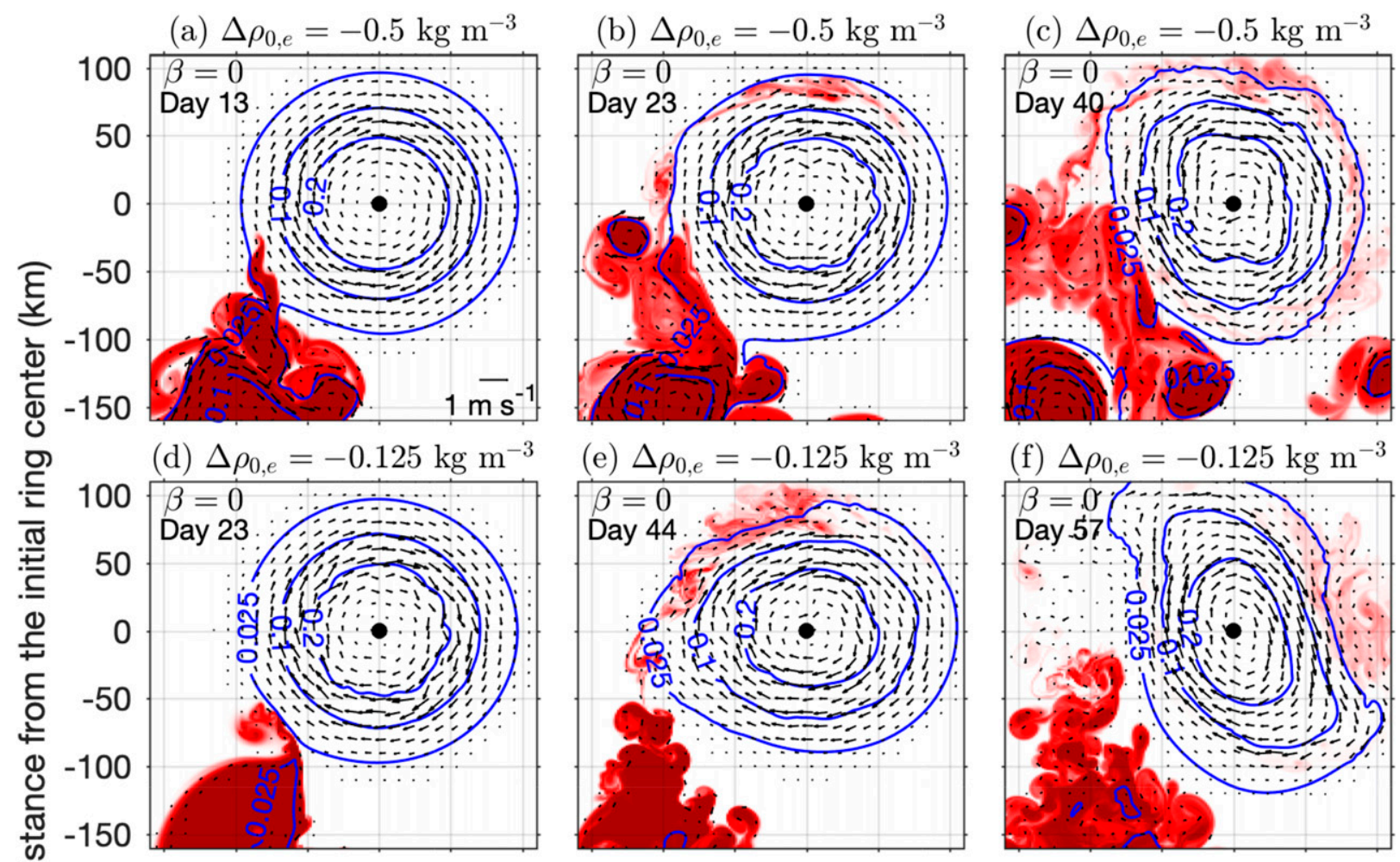

(h) $\Delta \rho_{0, e}=-0.125 \mathrm{~kg} \mathrm{~m}^{-3}$

(i) $\Delta \rho_{0, e}=-0.125 \mathrm{~kg} \mathrm{~m}^{-3}$
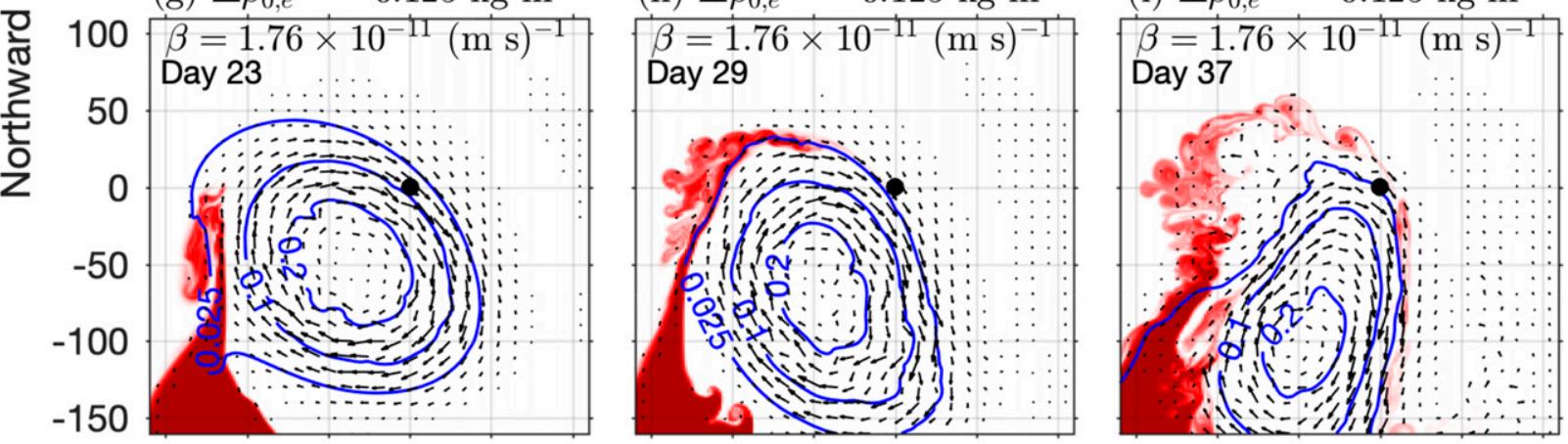

$-150-100-50$

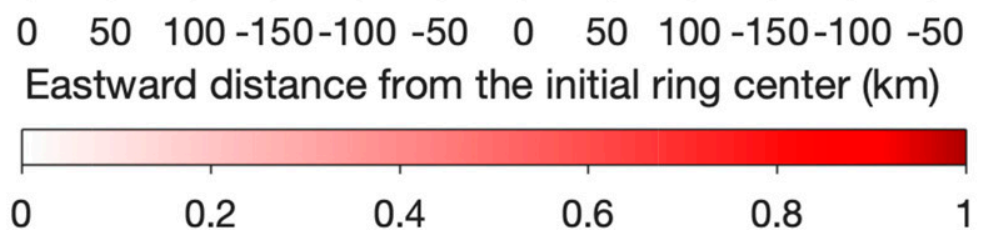

FIG. 11. Snapshots of sea surface height (blue contours), surface velocity (arrows), and surface concentration of eddy water $C_{e}$ (colors) from three sensitivity runs: (a)-(c) LDA Run 1 with $\Delta \rho_{0, e}=-0.5 \mathrm{~kg} \mathrm{~m}^{-3}$ and $\beta=0$, (d)-(f) LDA Run 2 with $\Delta \rho_{0, e}=-0.125 \mathrm{~kg} \mathrm{~m}{ }^{-3}$ and $\beta=0$, and (g)-(i) Beta Run with $\Delta \rho_{0, e}=-0.125 \mathrm{~kg} \mathrm{~m}^{-3}$ and $\beta=1.76 \times 10^{-11}(\mathrm{~m} \mathrm{~s})^{-1}$. Black dots represent initial centers of the rings; a scale of the velocity vectors is provided at the lower-right corner of (a).

of the eddy water relative to the surface ring water is essential for forming a spiral streamer. Formation of a warm spiral streamer over WCRs thus requires three different water masses: background slope water with the highest surface density, an old WCR with intermediate surface density, and a buoyant water mass (e.g., Gulf Stream or a younger WCR) with the lowest surface density. Note that the slope water with the highest density is necessary for the presence of both the old WCR and the buoyant eddy.

\section{c. Frontal subduction at the streamer edge}

CTD and VPR data suggest frontal subduction on both the exterior and interior sides of the warm spiral streamer (Fig. 4). We seek to reproduce that pattern in the model. In the control 
simulation, instability and waves develop on the eddy-ring interface during the initial radial intrusion of the eddy water (Fig. 7), and the associated vertical motions obscure analysis of the frontal subduction. To avoid this complexity, Subduction (SBD) Run 1 is carried out with the buoyant eddy placed closer to the ring center to skip the initial step of radial intrusion of the eddy water. It simulates the formation of the surface spiral streamer by the winding motion after radial intrusion of the eddy water has taken place (Fig. 12). In SBD Run 1, the center of the buoyant eddy at day 0 is at $x_{0, e}=-100 \mathrm{~km}$ and $y_{0, e}=-100 \mathrm{~km}, \sim 50 \mathrm{~km}$ closer to the ring center than the Control Run, and the edge of the buoyant eddy at day 0 is located at the $0.2 \mathrm{~m} \mathrm{SSH}$ contour of the ring where density of the surface ring and eddy waters are the same. Because the eddy water layer that intrudes into the ring is thinner than the main body of the buoyant eddy, as shown in the Control Run, the eddy thickness scale in SBD Run 1 is chosen to be $H_{e}=$ $60 \mathrm{~m}$. The other parameters of the buoyant eddy, including $\Delta \rho_{0, e}$, are the same as in the Control Run (Table 1). The description here focuses on the basic pattern of subduction, which resembles subduction in the Gulf Stream (Gula et al. 2014) and on the edge of a WCR (Zhang and Partida 2018). Detailed dynamical analysis of subduction process can be found in those studies and others in the literature (e.g., Mahadevan and Tandon 2006; McWilliams 2016; Spall 1995).

To demonstrate the influence of frontal subduction on the spiral pattern, SBD Run 2 is carried out with $\Delta \rho_{0, e}=0$ and all other parameters the same as in SBD Run 1, including the distribution of the passive tracers. The "eddy" in SBD Run 2 is only nominal, as the water marked by $C_{e}$ is completely passive with no density anomaly. There is thus no density gradient or frontal flow on the interface between the water marked with $C_{e}$ and the ring water. SBD Run 2 represents an unrealistic but useful model experiment in which winding motion of the ring distorts the marked neutral-density water and forms the spiral pattern, even though in reality the marked water would not be able to intrude into a WCR, as demonstrated by the LDA runs. For convenience, the neutral-density water marked by passive tracer $C_{e}$ in SBD Run 2 is still referred to as "eddy water" in the following description.

Initial development of the streamer and the basic pattern of spiral formation in the two SBD runs are similar: the anticyclonic ring current stretches the eddy water, sharpens the eddy-ring interface, and forms bended filaments; the filaments then evolve into spiral streamers with the same radial extent as the eddy water in the initial condition (Fig. 12). However, after day 6, the filament in SBD Run 1 appears much wider on the surface than in SBD Run 2. On day 6, the filament section north of the ring center is $16 \mathrm{~km}$ wide in SBD Run 1 and $8.5 \mathrm{~km}$ wide in SBD Run 2 (Figs. 12c,h). Vertical sections of the filaments on the north edge of the ring at day 6 show a consistent pattern with a wider filament in SBD Run 1 in the top $50 \mathrm{~m}$ (Fig. 13). Meanwhile, closer examination shows that edges of the eddy water streamer in SBD Run 1 are sharper than in those in SBD Run 2, even though they all have been greatly sharpened from the initial condition by the lateral stretching. At day 0, the maximum horizontal gradient of the eddy passive tracer on the surface $\left|\partial C_{e} / \partial n\right|_{\max }=1.8 \times 10^{-4} \mathrm{~m}^{-1}$.
Here, $n$ represents the outward radial direction starting from the eddy center. In SBD Run 1 at day $6,\left|\partial C_{e} / \partial r\right|_{\max }=7.2 \times$ $10^{-4} \mathrm{~m}^{-1}$ and $8.3 \times 10^{-4} \mathrm{~m}^{-1}$ on the exterior and interior edges of the spiral streamer, respectively; in SBD Run 2 at the same time, $\left|\partial C_{e} / \partial r\right|_{\max }=5 \times 10^{-4} \mathrm{~m}^{-1}$ on both exterior and interior edges of the spiral streamer. Here, $r$ represents the outward radial direction starting from the ring center. In addition, the eddy water lens in SBD Run 1 is $108 \mathrm{~m}$ thick in the vertical direction, thinner than the 116-m-thick lens in SBD Run 2 (Fig. 13). These differences in the streamers of two SBD runs are consistent with influences of frontal secondary flow in SBD Run 1, as described below.

We now examine density, velocity and passive tracer distributions on the streamer cross-section north of the ring center at day 6 in SBD Run 1 to investigate streamer-edge frontal subduction (Fig. 13). In SBD Run 1, the magnitude of maximum horizontal density gradient on the eddy-ring interface at day 6 has increased from the initial value of $|\partial \rho / \partial n|=0.33 \times$ $10^{-4} \mathrm{~kg} \mathrm{~m}^{-4}$ on the edge of the eddy to $|\partial \rho / \partial r|=1.1 \times 10^{-4}$ and $1.3 \times 10^{-4} \mathrm{~kg} \mathrm{~m}^{-4}$ on the exterior (north) and interior (south) edges of the streamer, respectively. This confirms that lateral stretching by the ring flow has intensified the density front on both edges of the eddy water streamer. There is also pronounced downward velocity of $>0.1 \mathrm{~mm} \mathrm{~s}^{-1}$ on both sides of the eddy water streamer and upward velocity of $\sim 0.06 \mathrm{~mm} \mathrm{~s}^{-1}$ inside the buoyant eddy water lens (Fig. 13d). This pattern of laterally sheared vertical velocity across the two adjacent fronts is an indication of the cross-sectional secondary flow that tends to relax intensifying fronts (e.g., Gula et al. 2014; Zhang and Partida 2018). The distribution of the surface ring water, initially in the top $30 \mathrm{~m}$, shows slanted downward extensions on the outskirts of the eddy water lens reaching 40 and $60 \mathrm{~m}$ on the exterior and interior sides, respectively (Fig. 13e). This pattern is very similar to the observed slanted layers of water of intermediate temperature and salinity on both sides of the warm lens (Fig. 4), and confirms that frontogenesis-induced frontal subduction occurs on both edges of the warm spiral streamer. The Rossby number of the flow on the streamer edges, Ro $=$ $U /\left(f L_{e}\right)$, is $O(1)$, consistent with the submesoscale nature of frontal subduction (McWilliams 2016). Here, $L_{e} \approx 5 \mathrm{~km}$ is the cross-front length scale and $U_{e} \approx 0.5 \mathrm{~m} \mathrm{~s}^{-1}$ is the alongfront speed, both at the edges of the eddy-water streamer.

This analysis yields a conceptual model of the secondary circulation (Fig. 14). Stretching of the eddy water by the primary anticyclonic ring flow intensifies the density front on both exterior and interior edges of the streamer, which triggers a double-cell secondary circulation on the streamer cross section. The weak secondary flow tends to relax the front by flattening the isopycnal on both edges of the streamer. As part of the secondary circulation, the buoyant eddy water inside the streamer moves upward, compressing the eddy water lens in the vertical direction, and the ring water on both sides of the eddy water streamer moves downward forming frontal subduction. On the surface, the secondary flow in the radial direction is divergent and connects the upward flow inside the eddy water lens with downward flows outside. The surface secondary flow thus pushes the exterior edge outward and the interior edge inward. This pattern of frontal secondary 


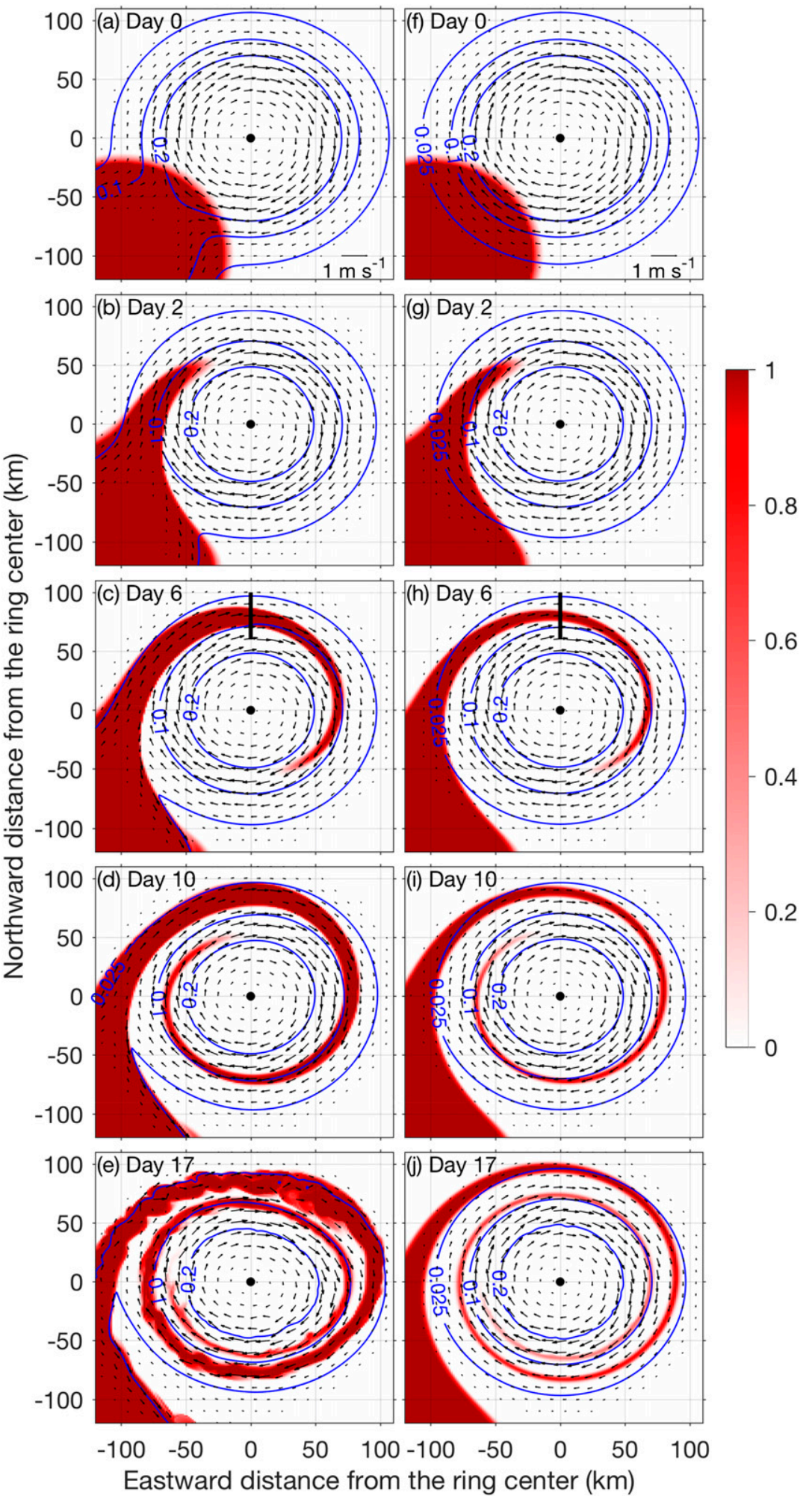

FIG. 12. Comparison between (a)-(e) SBD Run 1 with buoyant eddy and (f)-(j) SBD Run 2 of passive eddy at different times. Colors indicate the concentration of eddy tracer $C_{e}$, blue lines are contours of sea surface height with the interval of $0.1 \mathrm{~m}$, and arrows are the surface velocity with the scales at the lower-right corner of (a) and (f). The vertical black lines in (c) and (h) indicate the location of the cross sections shown in Fig. 13, below. 


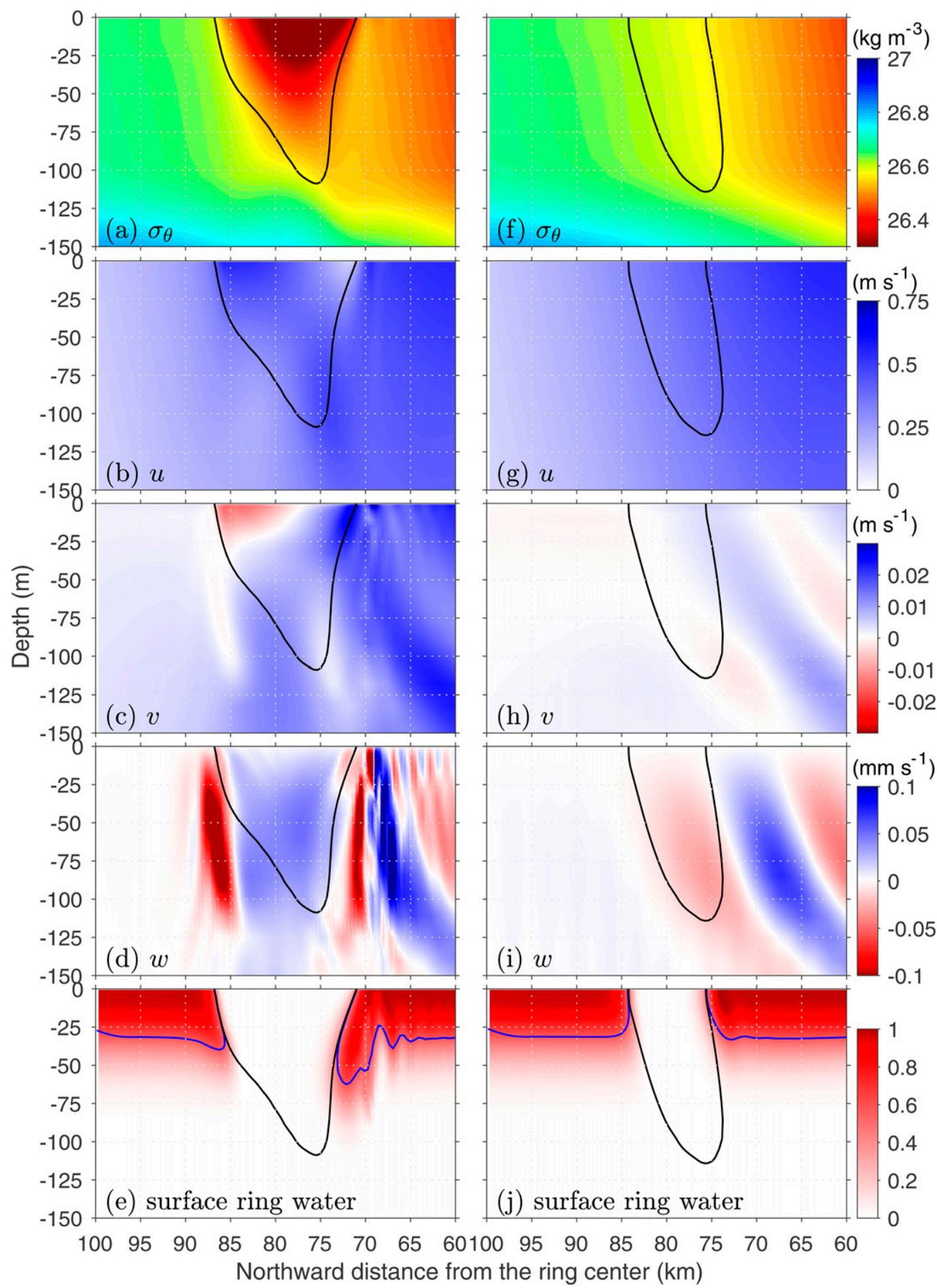

FIG. 13. Distribution of (a),(f) density $\sigma_{\theta}$; (b),(g) eastward velocity $u$; (c),(h) northward velocity $v$; (d),(i) vertical velocity $w$; and (e),(j) surface ring water concentration $C_{r s}$ on a cross-streamer section (see Figs. 12c and $12 \mathrm{~h}$ for the location) at day 6 from (left) Subduction (SBD) Run 1 and (right) SBD Run 2. The black lines in all panels depict the boundary of the eddy streamer water, and the blue lines in $(e)$ and $(j)$ indicate the boundary of surface ring water concentration. 


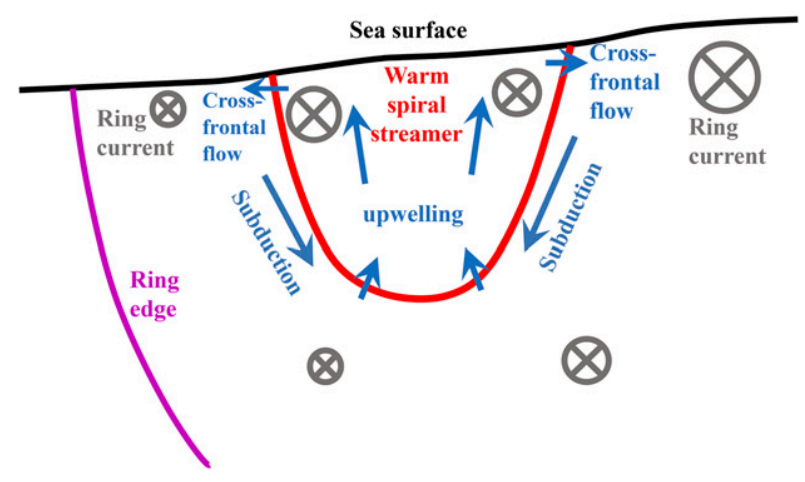

FIG. 14. A schematic of the streamer cross section showing major components of the circulation: the primary ring flow in gray and the secondary circulation around the warm spiral streamer in blue.

circulation is exactly opposite to the double-cell frontal secondary circulation triggered by the stretching of a cold dense filament in the Gulf Stream (Gula et al. 2014). The secondary flow at a stretching cold dense filament has a component of surface convergent flow that tends to squeeze the cold filament on the surface. In contrast, the divergent cross-frontal surface flow at the warm streamer studied here tends to widen the spiral filament and intensify the surface density gradient on both edges of the filament. They are consistent with the differences in the width of the spiral streamers and in the sharpness of the streamer edges in the two SBD runs.

Widening of the streamer by the frontal secondary flow strengthens the surface expression of the warm spiral over the ring. It also broadens the radial span of the frontal region on the exterior edge of the streamer. In SBD Run 1, the radial span of the exterior edge front of the streamer, that is, the radial distance between the bottom of the eddy water streamer and the streamer exterior edge on the surface, is $\sim 12 \mathrm{~km}$, wider than the $8-\mathrm{km}$ radial span of the streamer exterior edge in SBD Run 2 (Fig. 13). Because thermal wind balance of the exterior front drives an inflow of the buoyant eddy water to feed the streamer, broadening of the streamer exterior front allows more buoyant eddy water to intrude into the ring, as indicated by time series of the amount of buoyant eddy water residing in the WCR from the SBD runs (Fig. 15). In SBD Run 2, the amount of eddy water inside the ring is steady over time, because there is no secondary radial motion to widen the streamer and bring more eddy water toward the ring center.

\section{Discussion}

The spiral streamer formation mechanism described here requires a negative density anomaly relative to the surface ring water. It allows development of two crucial components of the streamer system: a density front and a thermal-wind-induced local anticyclonic flow at the nose of the intruding warm water that flows in the opposite direction as the large-scale flow of the WCR at the location. Because of the relatively strong current and the small length scale, the frontal flow is submesoscale with Rossby number order one. Nonlinear momentum advection of the local anticyclonic flow at the nose of the intruding warm

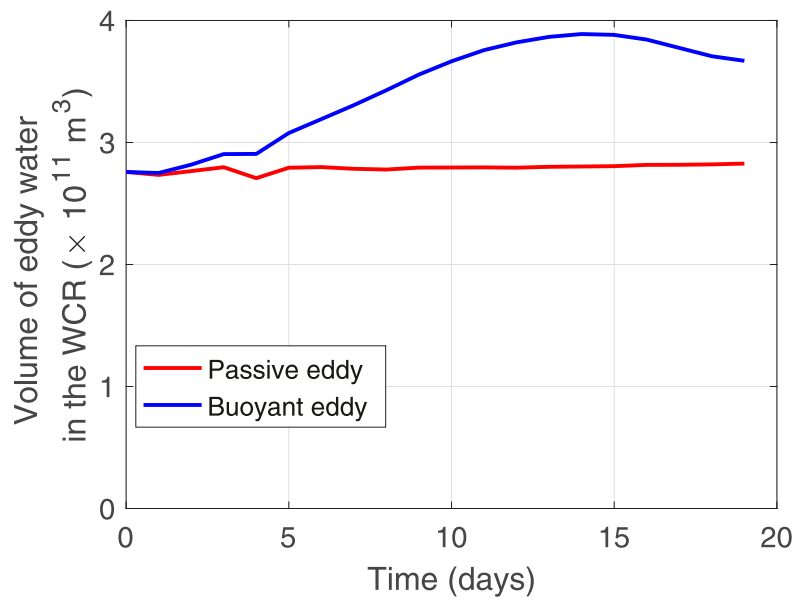

FIG. 15. Time series of the volume of marked eddy water inside the warm-core ring from SBD Run 1 (blue) and 2 (red). The boundary of the WCR is defined as the SSH contour of $0.025 \mathrm{~m}$.

water is thus important and pushes the intruding warm water in the radial direction toward ring center. The radial and rotary motions of the intruding warm water together form the spiral streamer. Nonlinear dynamics of the spiral formation is consistent with the different appearance of the spiral streamers in the real ocean (Fig. 1), as small deviations in initial conditions can be amplified by nonlinearity and result in finite-amplitude differences in the spiral patterns. During the spiral formation, the density fronts on the edges of the warm streamer are stretched and intensified by the ring azimuthal motion. This triggers secondary cross-sectional flow that tends to relax the intensifying fronts by repelling the streamer-edge fronts in the radial direction and subducting the surrounding surface water. This secondary flow enhances the surface expression of the warm spiral streamer.

As shown by LDA Run 2 (Fig. 11), in the absence of a density difference between the warm water and surface ring water, a WCR may still drive some warm water to move anticyclonically along its periphery, through expanding its sea surface signal over a larger area (Cherian and Brink 2016). However, with no local anticyclonic flow at the interface between the warm water and surface ring water, there is no centrifugal force pushing the warm water toward the ring center, and the warm water would not be able intrude into the ring generating the spiral pattern (Fig. 11). Dependence of the spiral pattern on density anomaly of the warm water also reflects the influence of radial versus azimuthal advection time scales. In our Control Run, the radial advection time scale is short enough for radial advection to create a significant radial offset between the nose and tail of the warm filament when it completes a circle around the ring. As magnitude of the density anomaly of the warm water decreases, flow at the eddy-ring interface weakens, and the radial advection time scale of the buoyant water increases. When the radial advection time scale becomes much larger than the azimuthal advection time scale, the radial advection will not be able to create a significant radial offset to form the spiral pattern when the warm filament 
completes a circle around the ring. Instead, the nose and tail of the warm filament would theoretically connect forming a loop around the ring, as depicted by Nof (1986). However, it is unclear whether such closed loops could actually form in the real ocean as other processes could disturb the system and prevent its formation. For instance, the loop pattern does not form in our LDA Runs because baroclinic instabilities interrupt the flow around the ring. Note that Nof's theory does not consider instabilities.

Next we discuss our results in the context of the three mechanisms of warm spiral formation associated with the overwash of a WCR, as proposed by Chapman and Nof (1988). Our observations show density fronts across the edges of the warm spiral streamer, which is not consistent with the first formation mechanism of a passive temperature gradient (with no density change) in an azimuthally uniform overwash of a ring by warm slope water. The modeling results presented here are also inconsistent with the second mechanism of fronts in the underlying ring causing inhomogeneous overwash of the ring and resulting in the spiral pattern. The WCRs simulated in this study do not contain any subsurface azimuthal gradients below the intruding buoyant water at the time of the spiral initial formation. Therefore, neither the first nor the second mechanisms proposed by Chapman and Nof is directly addressed here, and our results do not exclude the possibility of them forming a spiral streamer in another context. The third mechanism of initial instability of buoyant warm water concentrating an overwash event into a single spiral band has the same key ingredients as the intrusion dynamics presented here: negative density anomaly of the warm water relative to the surface ring water and initial instability on the edge of the warm water. The warm water intrusion presented here is localized, however, and occurs on a small section of the ring periphery. It is not a part of a widespread overwash event around the ring. However, conceptually, it could be useful to consider the present warm-water surface intrusion as a type of "localized overwash." That is, the radial motion of the buoyant water on the surface could be considered as the buoyant water rising up over the old WCR and moving toward a geopotential of the ring that is equal to its initial geopotential.

The requirement for a negative density anomaly of the intruding warm water is consistent with warm spiral streamers forming over relatively old WCRs. Newly formed WCRs tend to preserve water properties of the Gulf Stream. If a young ring collides with the Gulf Stream or another newly formed ring with similar water density, the localized overwash will not occur, and the spiral streamer examined in this study will not form. As the WCR ages and migrates within the Slope Sea, its surface water loses heat to the atmosphere (Schmitt and Olson 1985) and becomes denser. At this time, if the old ring with denser surface water collides with the Gulf Stream or a newly formed ring, a localized overwash of the old ring by buoyant warm water from the Gulf Stream or the young ring could occur, and the warm streamer will likely form. Therefore, there is likely a strong correspondence between relative density of a WCR with its surrounding waters and the way they interact, and it might be possible to infer the relative density from the pattern of the interaction.
Formation of some warm spiral streamers, to some extent, is similar to the vortex merging process (von Hardenberg et al. 2000). For instance, the event in June 2012 (Fig. 2) shows a small warm eddy being mostly engulfed by a large old WCR while forming the warm spiral streamer. Different from the merge of two identical vortices described by von Hardenberg et al. (2000), the buoyant eddy and old WCR in June 2012 differ in size and density characteristics (the eddy is much warmer than the WCR). However, it is possible that the buoyancy effect described here could work together with the vortex merging process in some cases causing most of the buoyant eddy water to rise to the center of the WCR. The details of this type of merging of vortices with differential buoyancy remain to be explored.

In the real ocean, the intrusion of surface buoyant water toward the ring center may be affected by other processes, such as surface divergent flows associated with wind-driven Ekman pumping in WCRs (Dewar and Flierl 1987). The divergent surface Ekman flow would tend to counter the inward motion of the buoyant water. A compensating upwelling occurs at the centers of mesoscale eddies with a typical speed of 0.1$1 \mathrm{~m} \mathrm{day}^{-1}$ (e.g., McGillicuddy et al. 2007). Assuming the upwelling occurs over an eddy core region of $50 \mathrm{~km}$ in radius, the divergent outward flow averaged over a 50-m-thick surface layer along the periphery of the core region is $<0.5 \mathrm{~km} \mathrm{day}^{-1}$. This is an order of magnitude weaker than the inward radial velocity of the buoyant water in the Control Run (Fig. 7). The influence of wind-driven surface divergent flow on the spiral formation is thus weak, which is confirmed by simulations forced by winds with speeds of $5-15 \mathrm{~m} \mathrm{~s}^{-1}$ (not shown). However, how other forces may modify the spiral pattern remains unclear.

Both mesoscale and submesoscale dynamics are crucial for the formation of the warm spiral streamers. Mesoscale processes, that is, WCRs and Gulf Stream, provide the underlying driving force, and submesoscale dynamics are a key component of the spiral formation. The submesoscale frontal secondary circulation includes strong vertical motions: subduction outside of the streamer and upwelling inside. These vertical motions have important biogeochemical implications. The submesoscale frontal upwelling within the ring could bring up nutrient-rich subsurface water to the euphotic zone and stimulate biological productivity in the ring surface layer where nutrients are normally depleted and phytoplankton biomass is normally low (e.g., Gaube et al. 2014). This localized process within the ring could also help explain the spatial inhomogeneity in chlorophyll concentration observed in old warm-core rings (e.g., Smith and Baker 1985). Meanwhile, subduction could be an important pathway of exporting biomass from the ring surface layer to depth (Fig. 4), as has been demonstrated elsewhere in the ocean (e.g., Omand et al. 2015). Understanding the influence of submesoscale dynamics on biogeochemistry of warm spiral streamers will require additional study.

\section{Summary}

Intruding warm spiral streamers are distinct surface features that often form in old WCRs in the northwest Atlantic Slope 
Sea after the WCRs collide with the Gulf Stream or other WCRs in the region. Satellite imagery of sea surface temperature shows their surface characteristics with size and flow pattern different from other spiral patterns in the ocean. Despite variation in the details, warm spiral streamers have a common feature of an inward radial offset between the nose and tail of the intruding warm water after the intruding warm water completes a circle over the WCR. Prior theoretical studies of ring collision and/or evolution processes do not fully explain the formation of the warm spirals. This study combines in situ measurements that capture the subsurface structure of a warm spiral streamer, and numerical models that reproduce the basic patterns of the observed warm spiral streamers. Simulations show that a warm spiral streamer only forms when the intruding warm water is less dense than the surface ring water, which explains the fact that warm spiral streamers mostly occur in relatively old WCRs that have lost some of their surface buoyancy.

Formation of the warm spiral streamers over WCRs is a nonlinear and submesoscale process that is forced by mesoscale dynamics. As the Gulf Stream or a younger WCR collides with an old WCR, buoyant warm water comes in contact with the old ring at the surface. The interface between the buoyant warm water and surface water of the old ring forms a density front with a thermal-wind-driven local anticyclonic frontal flow. Nonlinear momentum advection of the interfacial frontal flow, in the form of a local centrifugal force at the nose of the intrusion, pushes the intruding buoyant water toward the center of the WCR. At the same time, the intruding buoyant water is swirled by the underlying anticyclonic ring current. The radial and azimuthal motions of the buoyant surface water together form the spiral pattern. Meanwhile, submesoscale frontogenesis on both exterior and interior edges of the spiral streamer causes secondary cross-sectional flow that tends to entrain more warm water into the spiral streamer and widen the spiral streamer on the surface. This enhances the surface expression of the warm spiral streamer.

A key ingredient of the warm spiral streamers that this study focuses on is negative density anomaly of the intruding water relative to surface water on the periphery of the ring: the inward spiral provides a pathway for the intruding water to reach a geopotential consistent with its own. In the absence of a negative density anomaly, water surrounding a WCR will not be able to intrude into the ring even if it is subject to the influence of the ring and move anticyclonically along its periphery. In this case, the surrounding waters will likely stay on the outskirt of the ring or subduct underneath the ring. Note that the requirement of negative density anomaly does not necessarily apply to other spiral patterns in the ocean.

The warm spiral streamer this study focuses on represents a mechanism of water exchange between a WCR and its surroundings. This process could transport biological species across the lateral boundary of the ring and mix different biological communities. The secondary flow on the exterior and interior edges of a spiral streamer contains strong vertical motions, which could potentially affect biogeochemistry inside the WCR.
Acknowledgments. This work was initially motivated by an SST image (Fig. 1a) in the Fuglister Room at Woods Hole Oceanographic Institution, and we thank Peter Cornillon at University of Rhode Island for providing the data of that image. Authors W. G. Zhang and D. J. McGillicuddy are both supported by the National Science Foundation through Grant OCE 1657803.

Data availability statement. Satellite SST data were obtained from the MARACOOS THREDDS server (http://tds.maracoos. org/thredds/catalog.html). Shipboard in situ data are archived at the Biological and Chemical Oceanography Data Management Office (https://www.bco-dmo.org/project/748894).

\section{REFERENCES}

Andres, M., 2016: On the recent destabilization of the Gulf Stream path downstream of Cape Hatteras. Geophys. Res. Lett., 43, 9836-9842, https://doi.org/10.1002/2016GL069966.

Boyd, S. H., P. H. Wiebe, R. H. Backus, J. E. Craddock, and M. A. Daher, 1986: Biomass of the micronekton in Gulf Stream ring 82-B and environs: Changes with time. Deep-Sea Res., 33, 1885-1905, https://doi.org/10.1016/0198-0149(86)90084-1.

Buckingham, C. E., and Coauthors, 2017: Testing Munk's hypothesis for submesoscale eddy generation using observations in the North Atlantic. J. Geophys. Res. Oceans, 122, 67256745, https://doi.org/10.1002/2017JC012910.

Cenedese, C., R. E. Todd, G. G. Gawarkiewicz, and W. B. Owens, 2013: Offshore transport of shelf waters through interaction of vortices with a shelfbreak current. J. Phys. Oceanogr., 43, 905919, https://doi.org/10.1175/JPO-D-12-0150.1.

Chapman, R., and D. Nof, 1988: The sinking of warm-core rings. J. Phys. Oceanogr., 18, 565-583, https://doi.org/10.1175/15200485(1988)018<0565:TSOWCR > 2.0.CO;2.

Chaudhuri, A. H., J. J. Bisagni, and A. Gangopadhyay, 2009a: Shelf water entrainment by Gulf Stream warm-core rings between $75^{\circ}$ and $50^{\circ} \mathrm{W}$ from 1978-1999. Cont. Shelf Res., 29, 393-406, https://doi.org/10.1016/j.csr.2008.10.001.

—, A. Gangopadhyay, and J. J. Bisagni, 2009b: Interannual variability of Gulf Stream warm core rings in response to the North Atlantic oscillation. Cont. Shelf Res., 29, 856-869, https://doi.org/10.1016/j.csr.2009.01.008.

Cherian, D. A., and K. H. Brink, 2016: Offshore transport of shelf water by deep-ocean eddies. J. Phys. Oceanogr., 46, 35993621, https://doi.org/10.1175/JPO-D-16-0085.1.

- , and ——, 2018: Shelf flows forced by deep-ocean anticyclonic eddies at the shelfbreak. J. Phys. Oceanogr., 48, 1117-1138, https://doi.org/10.1175/JPO-D-17-0237.1.

Davis, C. S., F. T. Thwaites, S. M. Gallager, and Q. Hu, 2005: A three-axis fast-tow digital Video Plankton Recorder for rapid surveys of plankton taxa and hydrography. Limnol. Oceanogr. Methods, 3, 59-74, https://doi.org/10.4319/lom.2005.3.59.

de Marez, C., T. Meunier, M. Morvan, P. L'Hegaret, and X. Carton, 2020: Study of the stability of a large realistic cyclonic eddy. Ocean Modell., 146, 101540, https://doi.org/10.1016/j.ocemod.2019.101540.

Dewar, W. K., and G. R. Flierl, 1987: Some effects of the wind on rings. J. Phys. Oceanogr., 17, 1653-1667, https://doi.org/ 10.1175/1520-0485(1987)017<1653:SEOTWO >2.0.CO;2.

Early, J. J., R. M. Samelson, and D. B. Chelton, 2011: The evolution and propagation of quasigeostrophic ocean eddies. J. Phys. Oceanogr., 41, 1535-1555, https://doi.org/10.1175/2011JPO4601.1.

Eldevik, T., and K. B. Dysthe, 2002: Spiral eddies. J. Phys. Oceanogr., 32, 851-869, https://doi.org/10.1175/1520-0485(1987)017<1653: SEOTWO $>2.0 . \mathrm{CO} ; 2$. 
Evans, R. H., K. S. Baker, O. B. Brown, and R. C. Smith, 1985: Chronology of warm-core ring 82B. J. Geophys. Res., 90, 88038811, https://doi.org/10.1029/JC090iC05p08803.

Fox, M. F., and D. R. Kester, 1986: Nutrient distributions in warmcore ring 82-B April-August. Deep-Sea Res., 33, 1761-1772, https://doi.org/10.1016/0198-0149(86)90078-6.

Fuglister, F. C., 1963: Gulf stream '60. Prog. Oceanogr., 1, 265-373, https://doi.org/10.1016/0079-6611(63)90007-7.

Gaube, P., D. J. McGillicuddy, D. B. Chelton, M. J. Behrenfeld, and P. G. Strutton, 2014: Regional variations in the influence of mesoscale eddies on near-surface chlorophyll. J. Geophys. Res. Oceans, 119, 8195-8220, https://doi.org/10.1002/2014JC010111.

Gilbert, A. D., 1988: Spiral structures and spectra in twodimensional turbulence. J. Fluid Mech., 193, 475-497, https:// doi.org/10.1017/S0022112088002228.

Gula, J., M. J. Molemaker, and J. C. McWilliams, 2014: Submesoscale cold filaments in the Gulf stream. J. Phys. Oceanogr., 44, 2617 2643, https://doi.org/10.1175/JPO-D-14-0029.1.

Halkin, D., and T. Rossby, 1985: The structure and transport of the Gulf Stream at $73^{\circ}$ W. J. Phys. Oceanogr., 15, 1439-1452, https:// doi.org/10.1175/1520-0485(1985)015<1439:TSATOT>2.0.CO;2.

Houghton, R. W., R. D. Vaillancourt, J. Marra, D. Hebert, and B. Hales, 2009: Cross-shelf circulation and phytoplankton distribution at the summertime New England shelfbreak front. J. Mar. Syst., 78, 411-425, https://doi.org/10.1016/j.jmarsys.2008.11.023.

Hua, B.-L., C. Menesguen, S. Le Gentil, R. Schopp, B. Marsset, and H. Aiki, 2013: Layering and turbulence surrounding an anticyclonic oceanic vortex: In situ observations and quasigeostrophic numerical simulations. J. Fluid Mech., 731, 418-442, https://doi.org/10.1017/jfm.2013.369.

Joyce, T. M., 1984: Velocity and hydrographic structure of a Gulf Stream worm-core ring. J. Phys. Oceanogr., 14, 936-947, https:// doi.org/10.1175/1520-0485(1984)014<0936:VAHSOA > 2.0.CO;2.

— evolution of Gulf Stream warm-core ring 82B. Deep-Sea Res., 39 (1), S19-S44, https://doi.org/10.1016/S0198-0149(11)80003-8.

Linder, C. A., and G. G. Gawarkiewicz, 1998: A climatology of the shelfbreak front in the middle Atlantic bight. J. Geophys. Res., 103, 18 405-18 423, https://doi.org/10.1029/98JC01438.

Mahadevan, A., and A. Tandon, 2006: An analysis of mechanisms for submesoscale vertical motion at ocean fronts. Ocean Modell., 14, 241-256, https://doi.org/10.1016/j.ocemod.2006.05.006.

McGillicuddy, D. J., and Coauthors, 2007: Eddy/wind interactions stimulate extraordinary mid-ocean plankton blooms. Science, 316, 1021-1026, https://doi.org/10.1126/science.1136256.

McWilliams, J. C., 2016: Submesoscale currents in the ocean. Proc. Roy. Soc. London, A472, 20160117, http://doi.org/10.1098/ rspa.2016.0117.

—- and G. R. Flierl, 1979: On the evolution of isolated, nonlinear vortices. J. Phys. Oceanogr., 9, 1155-1182, https://doi.org/ 10.1175/1520-0485(1979)009<1155:OTEOIN > 2.0.CO;2.

—, M. J. Molemaker, and E. I. Olafsdottir, 2009: Line fluctuation growth during frontogenesis. J. Phys. Oceanogr., 39, 31113129, https://doi.org/10.1175/2009JPO4186.1.

Meinen, C. S., and D. S. Luther, 2016: Structure, transport, and vertical coherence of the Gulf Stream from the straits of Florida to the southeast Newfoundland ridge. Deep-Sea Res. I, 112, 137-154, https://doi.org/10.1016/j.dsr.2016.03.002.

Meunier, T., E. P. Sanz, M. Tenreiro, J. Ochoa, A. R. Angulo, and C. Buckingham, 2019: Observations of layering under a warm-core ring in the Gulf of Mexico. J. Phys. Oceanogr., 49, 3145-3162, https://doi.org/10.1175/JPO-D-18-0138.1.
Munk, W., L. Armi, K. Fischer, and F. Zachariasen, 2000: Spirals on the sea. Proc. Roy. Soc. London, A456, 1217-1280, https:// doi.org/10.1098/rspa.2000.0560.

Nof, D., 1986: The collision between the Gulf Stream and warmcore rings. Deep-Sea Res., 33, 359-378, https://doi.org/10.1016/ 0198-0149(86)90097-X.

Olson, D. B., and R. H. Backus, 1985: The concentrating of organisms at fronts: A cold-water fish and a warm-core Gulf Stream ring. J. Mar. Res., 43, 113-137, https://doi.org/10.1357/ 002224085788437325.

Omand, M. M., E. A. D'Asaro, C. M. Lee, M. J. Perry, N. Briggs, I. Cetinie, and A. Mahadevan, 2015: Eddy-driven subduction exports particulate organic carbon from the spring bloom. Science, 348, 222-225, https://doi.org/10.1126/science.1260062.

Schmitt, R. W., and D. B. Olson, 1985: Wintertime convection in warm-core rings: Thermocline ventilation and the formation of mesoscale lenses. J. Geophys. Res., 90, 8823-8837, https:// doi.org/10.1029/JC090iC05p08823.

Shchepetkin, A. F., and J. C. McWilliams, 2008: Computational kernel algorithms for fine-scale, multiprocess, long-term oceanic simulations. Handbook of Numerical Analysis. XIV: Computational Methods for the Atmosphere and the Ocean, P. G. Ciarlet, R. Temam, and J. Tribbia, Eds., Elsevier Science, 121-183.

Shen, C. Y., and T. E. Evans, 2002: Inertial instability and sea spirals. Geophys. Res. Lett., 23, 2124, https://doi.org/10.1029/ 2002 GL015701.

Smith, K. S., and R. Ferrari, 2009: The production and dissipation of compensated thermohaline variance by mesoscale stirring. J. Phys. Oceanogr., 39, 2477-2501, https://doi.org/10.1175/ 2009JPO4103.1.

Smith, R. C., and K. S. Baker, 1985: Spatial and temporal patterns in pigment biomass in Gulf Stream warm-core ring 82B and its environs. J. Geophys. Res., 90, 8859-8870, https://doi.org/ 10.1029/JC090iC05p08859.

Song, H., L. M. Pinheiro, B. Ruddick, and F. C. Teixeira, 2011: Meddy, spiral arms, and mixing mechanisms viewed by seismic imaging in the Tagus Abyssal Plain (SW Iberia). J. Mar. Res., 69, 827-842, https://doi.org/10.1357/002224011799849309.

Spall, M. A., 1995: Frontogenesis, subduction, and cross-front exchange at upper ocean fronts. J. Geophys. Res., 100, 25432557, https://doi.org/10.1029/94JC02860.

Stern, M., 1987: Horizontal entrainment and detrainment in largescale eddies. J. Phys. Oceanogr., 17, 1688-1695, https://doi.org/ 10.1175/1520-0485(1987)017<1688:HEADIL>2.0.CO;2.

Todd, R. E., G. G. Gawarkiewicz, and W. B. Owens, 2013: Horizontal scales of variability over the Middle Atlantic Bight shelfbreak and continental rise from finescale observations. J. Phys. Oceanogr., 43, 222-230, https://doi.org/10.1175/JPO-D-12-099.1.

von Hardenberg, J., J. C. McWilliams, A. Provenzale, A. Shchepetkin, and J. B. Weiss, 2000: Vortex merging in quasi-geostrophic flows. J. Fluid Mech., 412, 331-353, https://doi.org/10.1017/ S0022112000008442.

Warner, J. C., C. R. Sherwood, H. G. Arango, and R. P. Signell, 2005: Performance of four turbulence closure models implemented using a generic length scale method. Ocean Modell., 8, 81-113, https://doi.org/10.1016/j.ocemod.2003.12.003.

Zhang, W. G., and G. G. Gawarkiewicz, 2015: Dynamics of the direct intrusion of Gulf Stream ring water onto the MidAtlantic Bight shelf. Geophys. Res. Lett., 42, 7687-7695, https://doi.org/10.1002/2015GL065530.

- and J. Partida, 2018: Frontal subduction of the Mid-Atlantic Bight shelf water at the onshore edge of a warm-core ring. J. Geophys. Res. Oceans, 123, 7795-7818, https://doi.org/10.1029/2018JC013794. 